\title{
Adventure Tourism in the Canadian Arctic
}

\section{Chapter Summary}

The Canadian Arctic is defined and described and the numbers of tourists for the various regions estimated. The impact of adventure tourism on wildlife is documented, such as polar bear hunting and polar bear viewing, and the management approaches to conserve this iconic species are outlined; the possible spread of Giardia by tourists is discussed; and the impact of tourism on marine mammals and their management is described for beluga, narwhal and seals. There are impacts on birds too and on terrestrial vegetation in the tundra. Examples of aboriginal tourism are documented, including the development of the world-class Carcross mountain bike trails. Pleasure craft and cruise tourism have impacts, and the management approaches to minimise these are discussed. Finally the maintenance of the rich and diverse archaeological and historical sites in the face of tourist impacts is discussed.

\subsection{Introduction}

In the Canadian Arctic, tourism numbers are uneven across the region as a result of inade- quate transport infrastructure, scarcity of local products, a lack of skilled labour and insufficient marketing resources (Northern Development Ministers Forum 2008). In recent years, a summary of visitor statistics reveals that the region welcomed approximately 528,000 international and domestic visitors annually, with visitor spending totalling approximately C\$388 million: the figure for Yukon was 314,450 (Belik 2013); for Nunavut it was 30,525 (Belik 2013); for North West Territory 64,380 (Belik 2013); for Churchill (Manitoba): 20,747 (City of Thompson, Manitoba 2012); for Nunavik 88,000 (Tourism Quebec 2010); and for Labrador 10,394 (Government of Newfoundland and Labrador 2011). Spending was as follows: Yukon C\$200 million, Nunavut C\$40 million, North West Territory C\$99.5 million, Manitoba C\$21 million, Nunavik C\$18 million, Labrador C $\$ 9.9$ million. The Yukon is Canada's most visited Arctic destination because it has relatively easy road access from the USA via Alaska.

The growth of expedition cruising in the Canadian Arctic from increased access because of climate change is also resulting in negative cultural and environmental impacts in the form of people in places where they have never been before, the sale of marine mammal parts for souvenirs, and increased garbage in local communities (Maher 2012, Stewart et al. 2011; Klein 2010). 


\subsection{Definition of the Arctic in Canada}

The Arctic is defined as Canada north of $60^{\circ} \mathrm{N}$, as can be seen in Fig. 6.1, together with northern Quebec (Nunavik) and Labrador (Nunatsiavut), but, as Johnston (1995) points out, definitions of the Arctic can also be culturally (based on indigenous, aboriginal populations) and historically based constructs, and with changes in climate the definition will vary in the future. The definition probably, though, should be based on climate, permafrost and biogeography, and on this basis there can be a useful subdivision into the High Arctic and Sub-Arctic Canada. The High Arctic includes all the islands and archipela- gos north of the continental mass, most of which are uninhabited, but there are thinly scattered Inuit settlements in small coastal villages for the most part, mainly on the southern islands, and very few towns, except on the bigger islands, such as Baffin Island (Fig. 6.2). The landscape is dominated by glaciers and small ice caps which are in general retreat as a result of climate change; it is treeless, with tundra vegetation; there is permafrost and a periglacial landscape outside the glaciated areas with landforms like pingos, patterned ground and ice wedges; and the climate is cold, with average temperatures in January

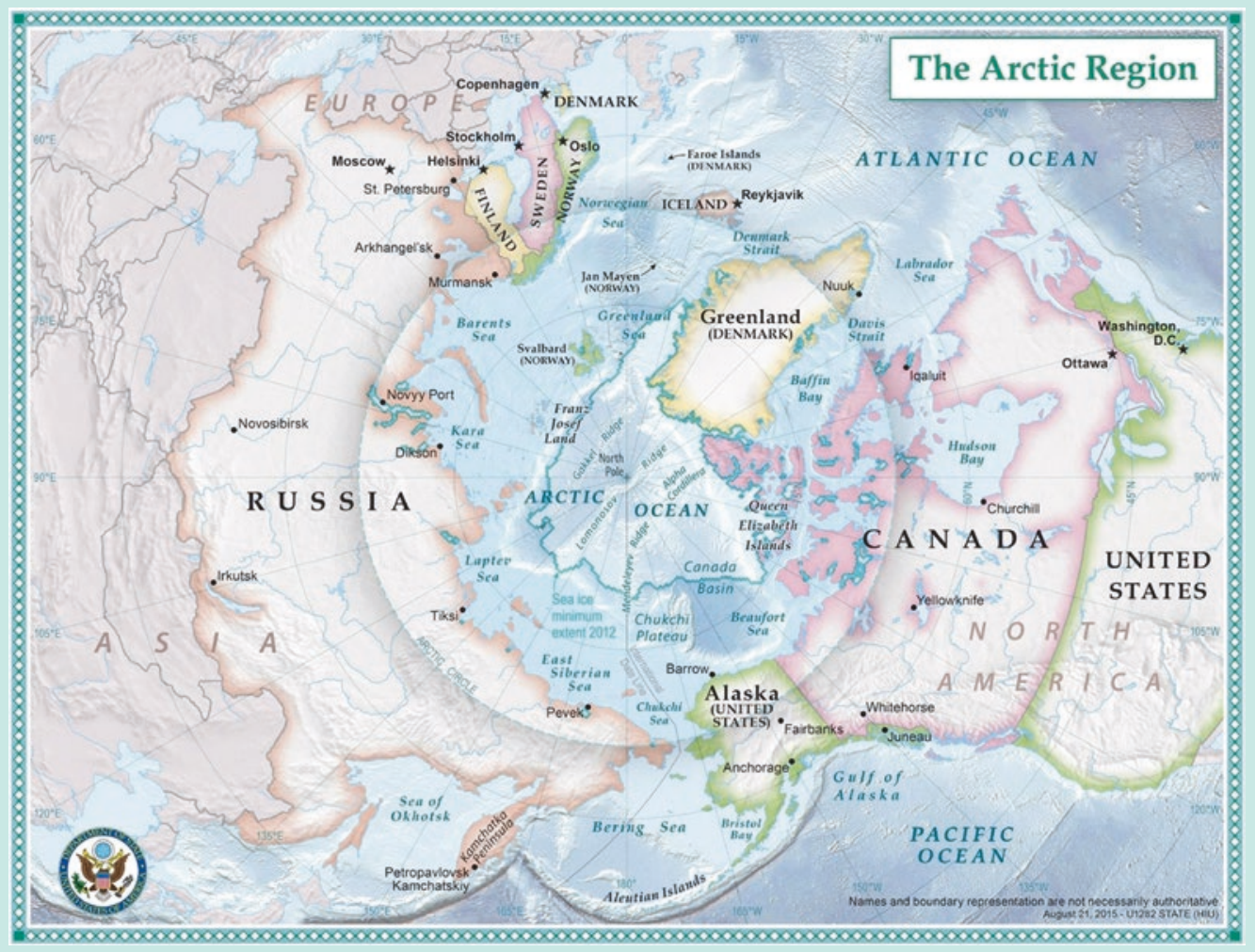

Fig. 6.1 The Arctic region. (Source: from US State Department http://www.state.gov/e/oes/ocns/opa/ar/ uschair/258202.htm) 


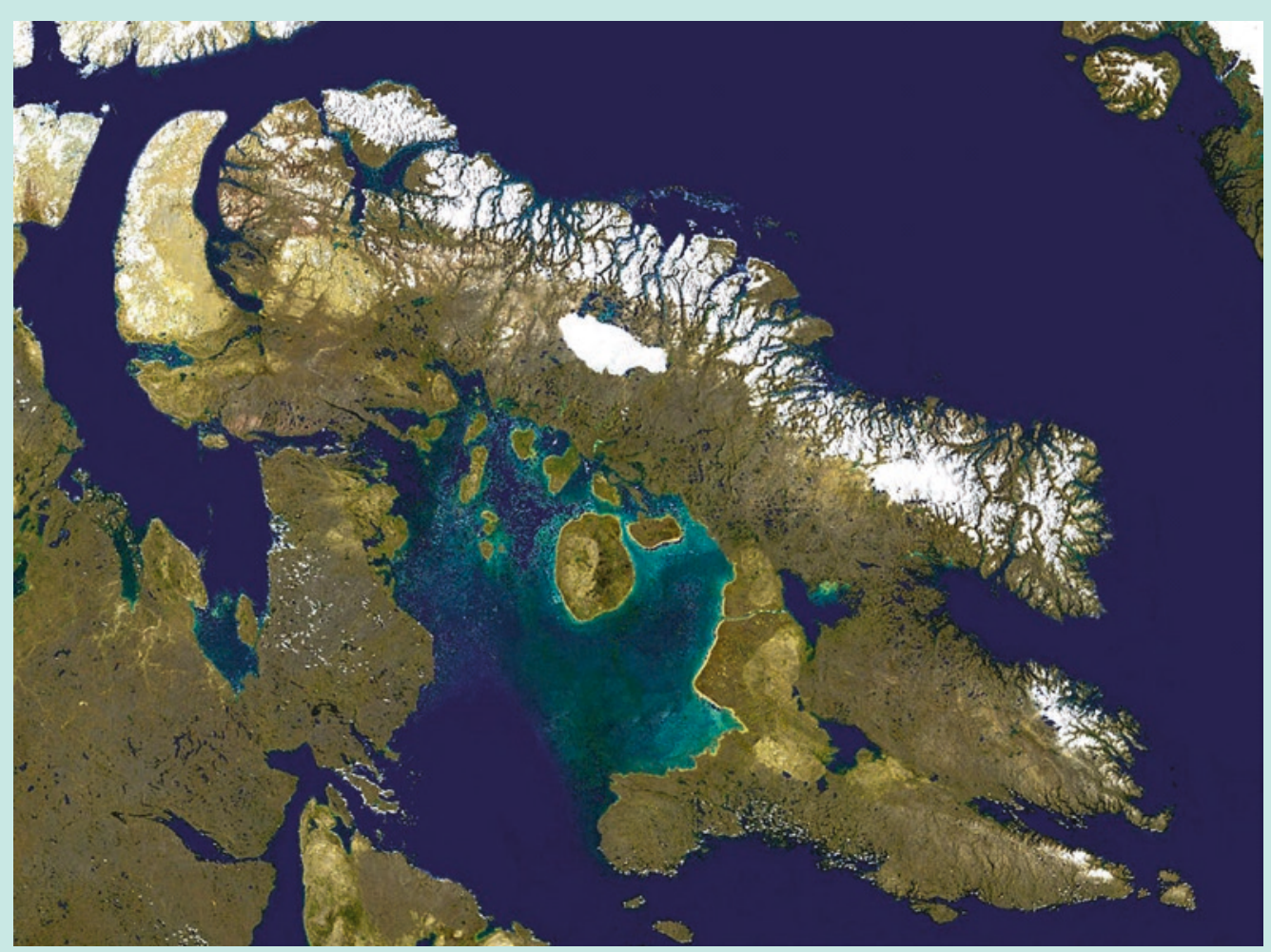

Fig. 6.2 Baffin Island. Note the small Barnes ice cap in the centre of the island. (Source: NASA World Wind 2006)

between $0{ }^{\circ} \mathrm{C}$ and $-34{ }^{\circ} \mathrm{C}$ and in July between $10{ }^{\circ} \mathrm{C}$ and $-10^{\circ} \mathrm{C}$ and a short summer season of less than three months. The archipelagos are bounded to the west by the Beaufort Sea, on the north-west by the Arctic Ocean and on the east by Greenland, Baffin Bay and Davis Strait, and the Canadian Arctic stretches over a vast area $-8000 \mathrm{~km}$ from west to east. To the south are Hudson Bay and the Canadian mainland. The archipelago consists of over 36,000 islands, the largest being Baffin Island, followed by Victoria Island, Ellesmere Island (Fig. 6.3), Banks Island, Devon Island, Axel Heiberg Island and Somerset Island. After Greenland it is the world's largest High Arctic area and has $39 \%$ of Canada's total land area but less than $1 \%$ of its population. It is sometimes called the Far North and divided into the Eastern Arctic with Nunavut and Nunavik, which is an autonomous part of Quebec province and Nunatsiavut, an autonomous part of Newfoundland province and Labrador. The Western Arctic is the north-west portion of the North West Territory and a small part of the Yukon, together called the Inuvialuit Settlement Region. The Sub-Arctic to the south of the High Arctic, with temperatures above $10^{\circ} \mathrm{C}$ for between one and three months, is composed mainly of boreal, coniferous forest, has First Nation Tribes and reserves and around 15\% of the Canadian population. 


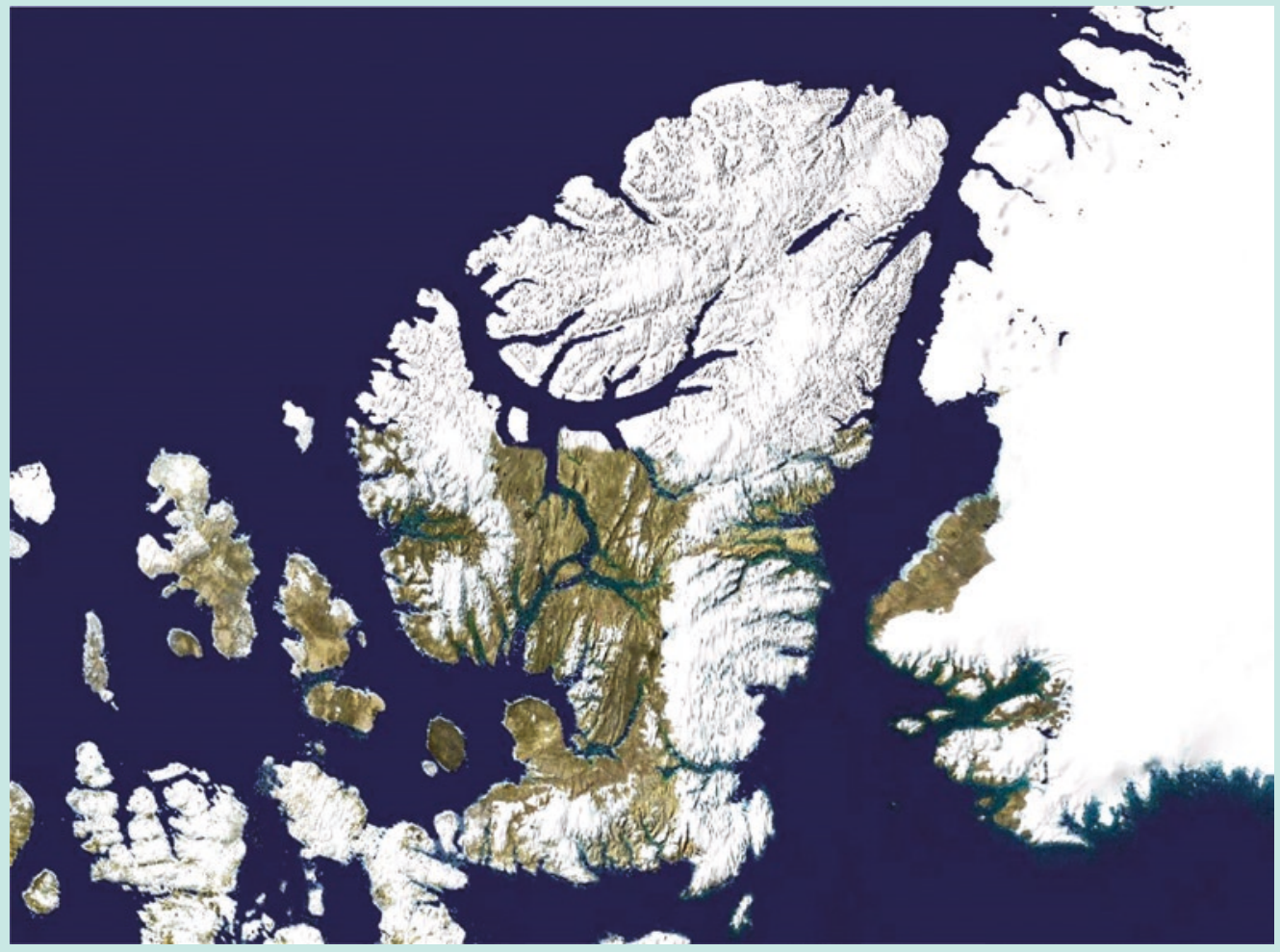

Fig. 6.3 Ellesmere Island. Note the large extent of ice cover. (Source: NASA (Worldwind.arc.nasa.gov))

Tourism is regarded as a relatively benign economic development alternative compared with that of energy and mineral exploration in the polar regions (Hall and Saarinen 2010a). The Canadian government has favoured the latter but with relatively little success. Tourism is also potential evidence for laying claim to polar territory as a form of economic use and is therefore part of the broader Canadian national polar geopolitical strategy. Hence the role of tourism has increased and tourism development is seen as a highly beneficial activity with the capacity to contribute to the wider socio-economic development of polar regions (Snyder 2007; Hall and Saarinen 2010b) and particularly in the Canadian Arctic (Robbins 2007). However, in the Canadian Arctic region tourism also benefits from energy and mineral exploration as the infrastructure required for oil, gas and other mineral development with respect to transport connectivity and accommodation is the same infra- structure that is also used by commercial tourism (Government of the Northwest Territories Industry, Tourism and Investment 2009). However, despite large investment in oil and mineral exploration, the returns have been relatively modest, and the producing mines, for example, in the North West Territory (NWT) there are three diamond mines (Diavik, Ekati and Snap Lake) employing 3300 people in total, whilst the tungsten mine at Canting employs only 204 (NWT Mineral Development Strategy, Government of NWT 2014). Nevertheless the NWT Geological Survey Strategic Plan 20172022 (2017) seems much more optimistic.

\subsection{Tourism Numbers}

The number of international tourists visiting Canada in 2011/2012 was at its lowest level since 1972, and whilst in 2000 the figures were 
19.6 million, they had dropped to 16 million by 2012. This was because of a combination of the 9/11 incident and the intense border security, the SARS outbreak of 2002, the global recession of 2008 and the recent unattractive exchange rates. However, recently there has been an increase, mainly owing to Chinese and other Asian tourists. The number of international tourist trips for 2017 for the Arctic regions, though, is extremely small, with the Yukon Territory having 1.63 million visits and Nunavut only 170,000, especially when compared with Ontario (9.77 million visits), British Columbia (5.7 million) and Quebec (3.14 million). It ought to be comparable with Greenland, which has extensively marketed the adventure tourism industry, and been successful, but this does not appear to be the case for Arctic Canada. Partly this is due to the inaccessibility of much of the region, the extremely high costs of internal flights and the high costs of accommodation too. Unlike from Greenland, there are no direct flights to the USA or Europe.

\subsubsection{North West Territory Tourism Numbers}

Tourism in the North West Territory (NWT) has shown marginal annual increases since 2000 but represent only the third-largest export, behind mining and petroleum products (Government of NWT 2014). In $2007 / 2008$, it is estimated that 79,000 tourists and business travellers spent $\mathrm{C} \$ 138$ million on NWT goods and services, of which just over C\$60 million is attributable to the accommodation and food services sector (Government of the
North West Territory Industry, Tourism and Investment (GNWTITI) 2009). Contributing more to the economy than the combined sales of agriculture, forestry, fishing and trapping, tourism is the largest renewable resource industry (GNWTITI 2009). By 2016-2017 tourist figures were at a record 93,910, although 20,000 of these were business travellers, who nevertheless took part in tourist activities. The growth of tourism and a breakdown of the reasons for visiting into six market sectors over a twelve-year period is shown in Table 6.1. NWT Tourism markets the area as a Spectacular World Class Tourist Destination, and this can be seen from Fig. 6.4A, B.

These figures show a growth since 2012 owing to a combination of factors, including the weak Canadian dollar and low gas prices, which provide a strong incentive for Canadians to vacation domestically and at the same time has attracted more visitors from overseas. Canada's reputation as a safe destination compared with some parts of the world must also have helped the growth. For example, between 2013-2014 and 2016-2017 tourists from China grew from 180 to 6200, with an annual growth rate of $55 \%$ during that period. This is likely to continue, especially as representatives from the NWT's tourism industry travelled to China in June 2018 with the goal of placing the NWT at the top of the minds of visitors from the industry's largest international market. The growth areas indicate a general increase in tourism along with outdoor adventure of $35 \%$ over the previous ten years from 2006-2016, aurora viewing increased spectacularly by $23 \%$ since $2016 / 2017$, whilst fishing and hunting declined. However, the growth has caused problems with tourist infra-

Table 6.1 NWT growth of tourism and market sectors involved

\begin{tabular}{|c|c|c|c|c|c|c|c|c|c|c|c|}
\hline & $05 / 6$ & $06 / 7$ & $07 / 8$ & $08 / 9$ & $09 / 10$ & $12 / 13$ & $13 / 14$ & $14 / 15$ & $15 / 16$ & $16 / 17$ & $17 / 18$ \\
\hline Hun & 1308 & 1216 & 984 & 942 & 757 & 500 & 510 & 510 & 510 & 480 & 482 \\
\hline Aurc & 0,200 & 7000 & 7297 & 5460 & 5400 & 5,700 & 1,700 & 6,400 & 4,300 & 9,800 & 29,814 \\
\hline Outdoor a & 2171 & 2077 & 2125 & 2098 & 1853 & 3100 & 1900 & 2100 & 2400 & 7400 & 7423 \\
\hline Fish & 7216 & 7726 & 7470 & 7284 & 6403 & 4800 & 5600 & 4300 & 4600 & 4200 & 4189 \\
\hline & 3,324 & 3,340 & 3 & 4,7 & 4,500 & 5,200 & 4,800 & 14,900 & 9,000 & 5,800 & 15,776 \\
\hline $\mathrm{g}$ friends and & 8942 & 9015 & 11,693 & 9261 & 12,910 & 13,800 & 14,100 & 17,200 & 12,200 & 15,900 & 15,927 \\
\hline Total & 40,386 & 43,161 & 44,692 & 39,795 & 41,823 & 53,100 & 58,610 & 55,410 & 63,010 & 73,580 & 73,610 \\
\hline
\end{tabular}

Adapted from NWT Marketing Plan 2018-2019 and the Tourism 2015 New Directions for a Spectacular Future, NWTs Industry, Tourism and Investment (2011) 

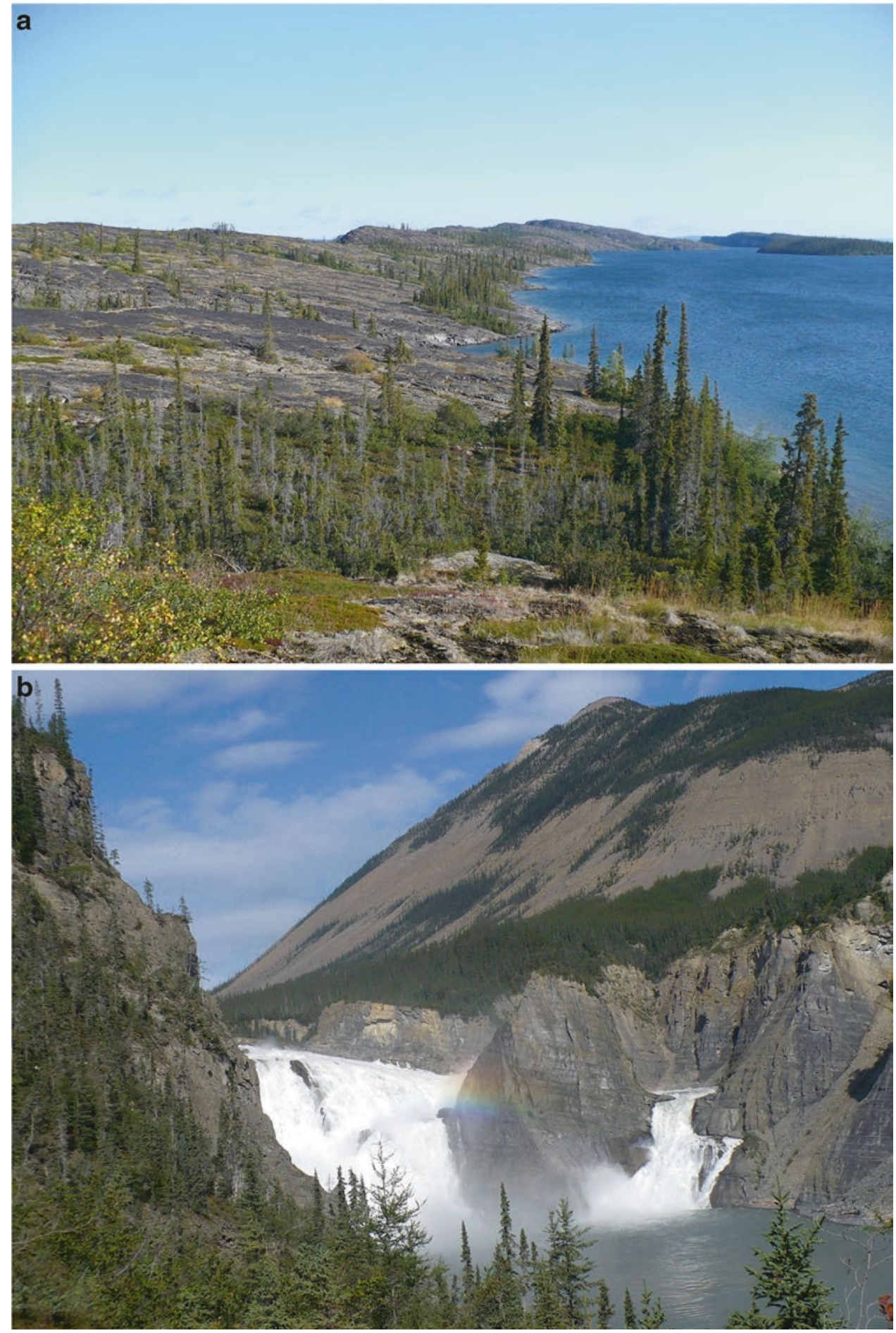

Fig. 6.4 (A) Utsingi Point, the eastern arm of the Great Slave Lake, North West Territories, eastern edge of the proposed Thaydene Nene National Park. (Photo: Paul
Gierszewski). (B) Nahanni National Park Reserve, North West Territories, Virginia Falls (Nailicho). (Photo: Paul Gieraszewski) 
structure and there has been a hotel room shortage in Yellowknife on occasions.

Nevertheless, despite this growth, national park visiting has remained low, as can be seen from Table 6.2, which may in part be due to budget cuts to Parks Canada, but is more likely to be due to the extreme inaccessibility, especially of Aulavik on northern Banks Island and Tuktut Nogait, where the main access is by charter aircraft from Paulatuk. All the parks have spectacular landscapes, including mountains, lakes (Fig. 6.4A) and rivers, ideal for paddling, hiking and climbing in Nahanni (Figure 6.4B), and magnificent wildlife. For example, Aulavik has two-thirds (over 10,000) of the world's musk oxen (Fig. 6.5), Tuktut Nogait has the 68,000 Bluenose caribou herd and Wood
Buffalo has wood bison, wolves and black bears. The Wood Buffalo Park has year-round road access from Fort Smith, which is reflected in the visitor numbers. The newest national park was created in 2014, the Náats'ihch'oh, which is 5000 sq. km of Alpine scenery, with excellent paddling on the Natla, Keele, Broken Skull and headwaters of the Nahanni rivers.

The outdoor adventure market segment has been identified as a major growth area in every region of the Canadian Arctic, as can be seen from the next section, although many of these segments overlap. In NWT, recreational hunting and fishing, outdoor adventure and aurora viewing are seen as growth areas; the Yukon is popular with those seeking adventure challenges, with

Table 6.2 National park visitation in the NWT

\begin{tabular}{|l|c|c|c|c|c|}
\hline & $2012 / 13$ & $2013 / 14$ & $2014 / 15$ & $2015 / 16$ & $2017 / 17$ \\
\hline Aulavik & 8 & 8 & 10 & 0 & 8 \\
\hline Nahanni & 840 & 760 & 800 & 1044 & 1082 \\
\hline Tuktut Nogait & 7 & 21 & 8 & 4 & 2 \\
\hline Wood Buffalo & 1790 & 3364 & 2604 & 3119 & 3340 \\
\hline
\end{tabular}

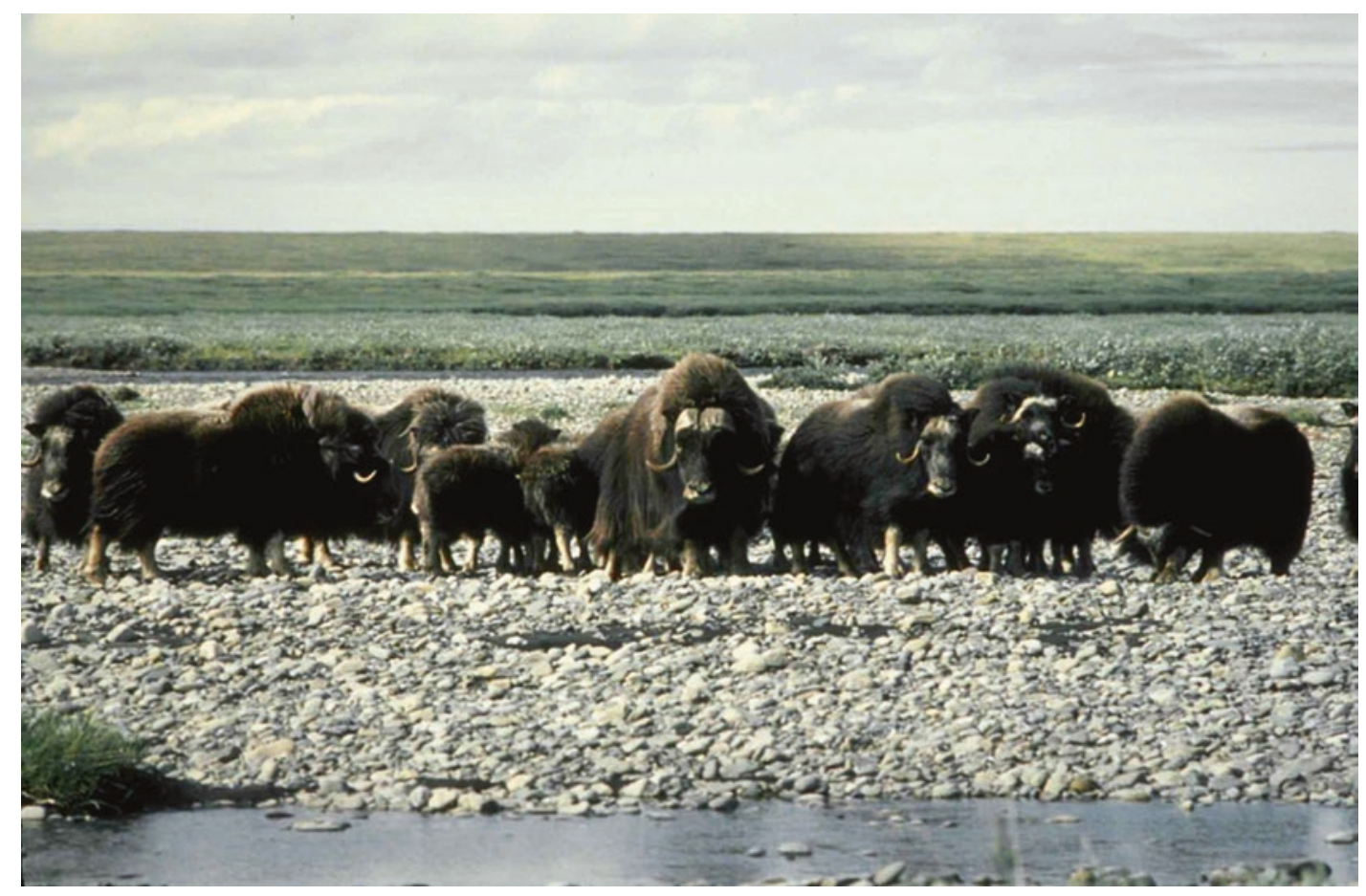

Fig. 6.5 Nunivak musk oxen in defensive formation. (Source: US Fish and Wildlife Service) 
Table 6.3 Visitation to the Yukon

\begin{tabular}{|l|l|l|r|l|l|}
\hline & 2012 & 2013 & 2014 & \multicolumn{1}{l}{2015} & 2016 \\
\hline Overnights & 219,000 & 274,000 & 231,000 & 309,000 & 322,000 \\
\hline Air passenger arrivals at Whitehorse & 147,075 & 147,079 & 153,353 & 156,018 & 169,448 \\
\hline Alaska border crossings & 467,616 & 471,157 & 481,559 & 489,600 & 528,707 \\
\hline Campsite usage & 16,767 & 17,916 & 19,627 & 23,964 & 26,254 \\
\hline
\end{tabular}

Source: Adapted from Tourism Yukon 2016 end-of-year report

scenic outdoor travellers and with cultural explorers; and in Nunavut adventure tourism, cultural tourism and consumptive tourism (hunting and fishing) are looked at as having growth potential.

\subsubsection{Tourism Numbers in the Yukon}

In the Yukon there has been a steady growth of tourism numbers, as can be seen from Table 6.3, and the 2016 figures reflect just under a 10\% growth from the previous year.

\subsubsection{Tourist Numbers in Nunavut}

In relation to tourism in Nunavut, the baseline data published in 2007 (Datapath 2007) suggested approximately 9300 tourists visited the territory between June and October 2006, with 2100 visiting on a cruise. Based on these figures, the summer tourism industry was worth nearly C \$4.4 million dollars to Nunavut, with over half being spent in the Baffin region. Of this total, cruise tourism was estimated to generate $\mathrm{C} \$ 2.1$ million dollars to the territory (Datapath 2007). However, the most recent figures available suggests a growth in numbers to 16,750 in 2015 (Nunavut Tourism 2016), which represented a small increase in tourists since 2011. The breakdown by segment was: business travellers 11,550 (who also carried out tourist activities); cruisebased travellers 2750; land-based travellers 1130; and those visiting friends and relatives 1155 . The cruise category was the only segment that had shown real growth since 2011, with numbers up from 1890. In the three areas of Nunavut, Qikiqtaalik (Baffin and Ellesmere Islands) dominated, with 14,572, Kivalliq (Keewatin) had
1340, and Kitikneot (the south and eastern parts of Victoria Island, with adjacent parts of the mainland as far as the Boothia peninsula, together with King William Island and the southern part of Prince of Wales Island) 3350.

\subsubsection{The Strengths/Weaknesses/ Opportunities/Threats Facing Nunavut Tourism}

\section{- Strengths}

Spectacular scenery Raw nature Unique . Off the beaten path . True northern experience 'The REAL north' . Untouched · Wildlife (animals, flora and fauna)

Photography · Expedition travel . History · Friendly, unique people . Culture - Real outdoor activities: dog sledding, fishing $\cdot$ Authentic

- Weaknesses

Very expensive - Little tourism infrastructure - Little consolidation of product/positioning - Limited sources of information - Limited audience (experienced, wealthy travellers) · Potentially dangerous or risky for DIY travelling Typically a visitor needs a guide or needs to be accompanied/ fairly inaccessible · Internal transportation required - Short season - Absence of clear positioning, no sense of what the trip will be like or the benefits . No itineraries or trip plan ideas . Little understanding of how to integrate with the land and people 


\section{- Opportunities}

Undiscovered land - Can start from a white canvas, no negative imagery-can shape potential traveller opinions Unique - Sherpa guides/personal guides 'Expeditions' positioning - Customised, full nature experience - Capitalise on business travel. Get existing visitors to spend more leisure time and spend money to support expanded infrastructure - New model for ecotourism Expedition travel made safe - Nunavut positioned as an Arctic 'kingdom' or special place - As close to the north pole as you are going to get

\section{- Threats}

Bad commercialisation/tourism - Uncontrolled tourists get hurt and create a bad name - Bad press as tourism grows Disrupting an intact, preserved culture (Adapted from Nunavut Visitor Exit Survey (2015))

For the land-based Leisure Travellers hiking is by far the most popular activity, especially in parks, sanctuaries and near heritage rivers (Nunavut Tourism 2016), but town-based activities are also popular (visiting museums, cultural centres, shopping areas). As would be expected, an equal number are active in the outdoors: camping, hunting, fishing, wildlife and bird viewing. The activities that they took part in are as follows, in percentages:

hiking 62; visiting museums or cultural centres 45 ; visiting a park, sanctuary or heritage river 43 ; browsing/purchasing art/carvings/local products 33 ; overnight camping or igloo experience 30 ; visiting friends and/or relatives 30; recreational hunting or fishing 29 ; wildlife and bird viewing 25 ; cultural experiences, visiting elders, throat singing 21 ; viewing the Northern Lights 16; kayaking/rafting/canoeing 14; cruise or boat tour 14; dog-sled/skidoo/ skiing 9; attending an event or festival 8; attending a conference, convention or trade show 5; Inuit language training 2; attending meetings 1 ; other 4 .

Licensed recreational hunting and fishing revenues have significantly declined in the last ten years, 2006-2016. Polar bear hunts have decreased from 135 in 2006-2007 to 24 in 2009-2010, owing in part to the ban on exporting polar bear skins to the USA. Caribou hunts declined from 2016 in 2006-2007 to 157 in 2010-2011 whilst musk ox hunts decreased from 166 in 2006-2007 to 119 in 2010-2011. This decline is paralleled by the growth of ecotourism activities, which have a supposed low environmental impact. However, it appears that this has resulted in insufficient outfitters (people who supply all the equipment and services for hunting) to meet the current hunting and fishing demand (Nunavut Tourism 2012).

\subsection{Impacts of Adventure Tourism on Wildlife}

Some of the main attractions to tourists in Arctic Canada are the polar and tundra animal and bird species, particularly the iconic polar bear, some of the whale species, the musk ox and the wood bison-although the last of these only really in the Wood Buffalo National Park in the south of the region. There are two activities associated with these animals: wildlife viewing, which ought not to have much environmental impact, and sport and trophy-hunting, which could have an effect on the population numbers. These are discussed by Chanteloup (2013) from Nunavut, who suggests that, although wildlife viewing seems to fit Westerners' expectations much better, it is not necessarily the case that it is a more environmentally friendly tourism type.

\subsubsection{Polar Bear Hunting}

The Canadian Arctic is the home range for approximately half of the $25,000-30,000$ polar bears living in the circumpolar world, and most of Canada's population is found in Nunavut (Fig. 6.6). There is controversy between the perceptions of the Inuit that polar bears are increasing in numbers and the views of scientists who suggest that as a result of global warming there are fewer bears, and this has led to disputes over 
Fig. 6.6 Polar bear. (Author Dave Olsen, US Fish and Wildlife Service)

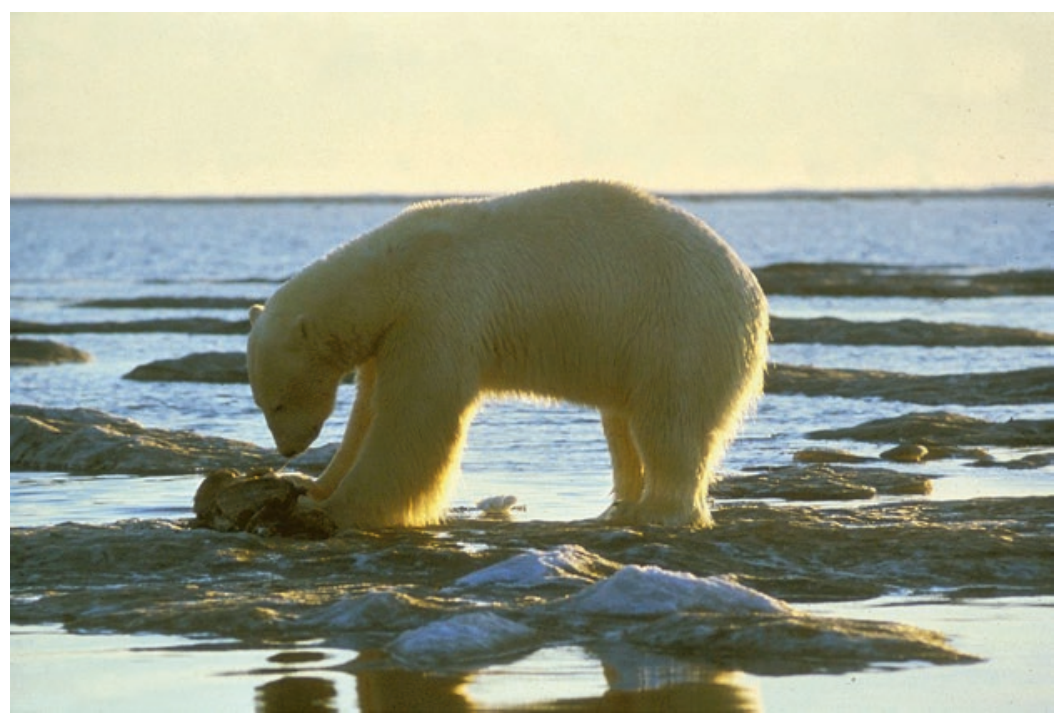

hunting quotas (Tyrrell 2006), particularly whether they should decrease. The polar bears are the world's largest terrestrial carnivores and are among the most carefully managed species (Fikkan et al. 1993) in the northern hemisphere. Between 500 and 650 polar bears are hunted annually in Canada (see Table 6.5), far more than are hunted in Greenland or Alaska, whereas Norway and Russia, the other nations with significant polar bear populations, have banned all forms of polar bear hunting owing to non-sustainable uses of bear populations such as trophyhunting. The majority of the harvest in Canada is taken by the Inuit of Nunavut. For Nunavummiut (regional Inuit people), polar bear meat remains an important item in their diet and, with the advent of a fur trade with non-Inuit in the early twentieth century, polar bear hides became an economic resource; the sale of the skins is still a part of the contemporary economy. Under the multilateral Agreement for the Conservation of Polar Bear, Canada has a legal and scientifically managed polar bear hunt (Lentfer 1974). Inuit are permitted to sell bears from their annual quota to non-aboriginal recreational hunters. Typically, each year Nunavummiut make between seventyfive and ninety bears available to recreational hunters from the USA, western Europe, Japan and Latin America. With the average cost of a recreational polar bear hunt now between $\mathrm{C} \$ 35,000$ and $\mathrm{C} \$ 60,000$, this trophy-hunting is now at least as important in economic terms as the traditional polar bear fur trade. Polar bear trophy-hunting may be one of the most taxing hunts anywhere in terms of the toll it exacts on hunters and their equipment. Conducted mainly between March, when temperatures average $-25^{\circ} \mathrm{C}$, and the end of May, when it may be as warm as $+5{ }^{\circ} \mathrm{C}$, client hunters travel across the sea ice with an Inuit guide and his hunt assistant on hunts lasting up to ten days, often covering 300-500 km during a trip. By regulation, trophy-hunting must be done using traditional means, which is by dog team, and the conditions are frequently extreme and taxing for recreational hunters.

The most obvious benefit Inuit derive from recreational polar bear hunting is the financial contribution to the communities that host and stage trophy hunts (for example, Foote and Wenzel 2008, 2009; Tyrrell 2009). Such benefits most obviously accrue to the individuals who work as guides or are otherwise involved in trophy-hunting, such as the assistants, but there are also other returns-some economic and others less apparent-that transcend wages to individual Inuit. A polar bear trophy hunt is expensive, with the cost paid by client-hunters to the southern expediters (for example, Canada North Outfitting, who have their head office in Edmonton, Alberta, www.canadanorthoutfitting. 
Table 6.4 The polar bear conservation hunt: economic attributes

\begin{tabular}{|l|l|l|l|}
\hline General features in & Clyde River & Resolute Bay & Taloyoak \\
\hline $\begin{array}{l}\text { (A) Annual polar bear quota } \\
\text { (B) Annual sport hunts }\end{array}$ & 21 & 35 & 20 \\
\hline (C) Local outfitters & 10 & 20 & 10 \\
\hline (D) Wholesale hunt price & 3 (private) & 1 (private) & 1 (community) \\
\hline (E) Local outfitter price & $\$ 30,000$ & $\$ 34,500$ & $\$ 34,500$ \\
\hline Local distribution $^{\mathrm{b}}$ & $\$ 18,400$ & $\$ 19,000$ & $\$ 13,000$ \\
\hline (F) Guides/helpers & & & \\
\hline (G) Total guides' wages & & $5 / 9$ & $5 / 9$ \\
\hline (H) Total helpers' wages & $10 / 10$ & $\$ 180,000$ & $\$ 47,300$ \\
\hline (I) Gratuities (average) & $\$ 51,000$ & $\$ 100,000$ & $\$ 38,200$ \\
\hline (K) Polar bear meat $(\mathrm{kg})$ & $\$ 41,000$ & $\$ 34,000$ & Unknown \\
\hline (L) Polar bear meat value & $\$ 42,000$ & $c .3000$ & $c .1400$ \\
\hline
\end{tabular}

Source: Adapted from Foote and Wenzel (2009)

${ }^{a}$ Not factored are fees to polar bear tag holders, additional charter or scheduled airline fares, local purchases of arts and handicrafts, and the cost of hunt consumables (food).

${ }^{\mathrm{b}}$ Total fee paid to southern broker by the individual hunter for his/her hunt (C\$)

${ }^{\mathrm{c}}$ Contract fee between southern-based wholesaler and local outfitters

${ }_{\mathrm{d}}$ This data refers to equipment purchased with recreational hunt wages and is incomplete

${ }^{\mathrm{e}}$ Based on $\$ 8.50$ per kg of imported meat (averaged across the communities)

${ }_{\mathrm{f}}^{\mathrm{A}}$ As polar bear meat is generally used for dog fodder at Taloyoak, the value imputed to the meat entering the community is based on the price of imported dry dog food

$\mathrm{com} /$ ) that are the link between the sport hunt community and the Inuit in Nunavut. In fact, the portion of the money that ultimately enters northern communities ranges from around $43 \%$ (at Taloyoak) to about $60 \%$ (at Resolute Bay) of the price paid to wholesalers, according to Foote and Wenzel (2008). Even though a substantial proportion of the fee paid by a visitor hunter goes to a southern expediter, hosting polar bear trophyhunting offers distinct economic benefit to northern communities and to the Inuit who participate in it as community outfitters, guides and hunt assistants (see Table 6.4). This economic benefit, however, is disputed by the Humane Society of the USA (2013). Nevertheless, Dowsley (2009a, b) suggests that each recreational hunt provides about twenty times the monetary value of a polar bear taken in a subsistence hunt.

Almost all the Inuit from Clyde, Taloyoak and Resolute who guide are middle-aged Inuit who possess extraordinary traditional skills, are able to 'age' a polar bear track, control a team of fifteen sled dogs and respond to sudden changes in the weather or sea ice (Foote and Wenzel 2008). Some also lack sufficient command of English to hold high-paying wage employment, and indeed many prefer to work on recreational hunts not only because such hunts offer a high return but also because as Inuit the guides identify with being a hunter and consider their principal occupation to be hunting.

Additionally, communities retain virtually all the meat from recreationally hunted polar bears. As this amount of food (up to $200 \mathrm{~kg}$ per bear) would almost certainly have been taken by subsistence hunters, counting the meat from trophy kills as a 'benefit' may seem a form of doublecounting. However, it must be remembered that the nearly $2000 \mathrm{~kg}$ received by the community via the recreational hunt comes at essentially no cost as the 'expenses' are covered by the client hunter.

Maybe the most important benefit is that by working on the recreational hunt, guides and assistants benefit from the simple fact of 'being on the land'. For older Inuit, time spent outside the communities is part of being truly Inuk. It is a time and place to exercise traditional skills that range from the actual tracking of a bear to reading the environment for hazards to handling dog teams. Furthermore, as many of the younger Inuit who function as hunt assistants may have had little, if any, opportunity to hunt polar bear themselves, working under the tutelage of an experi- 
enced hunter leads to a transfer of skills in the best milieu for learning about both polar bear and the land skills that formal schooling and life in the communities rarely afford.

The benefits to the recreational hunter, as Wenzel and Bourgouin (2003) note, is that, after the rarity of polar bear trophies, it is the experience of traveling and living with Inuit upon which those who have hunted in Nunavut most frequently comment. Traditional skills are not only still a part of modern Inuit life but are essential to it. Moreover, many come away realising that the role of tradition among Inuit is not limited to the pursuit of a bear or a level of comfort with the environment, but is also a matter of the closeness that exists among Inuit and between them and the Arctic. There are other positive cultural outcomes for communities that offer recreational hunts, and these include the revival of dog-mushing, the preservation of traditional sewing and the preservation of hunting and survival skills (Dowsley 2009a, b).

It was not until 1956 that restrictions were placed on the Inuit people of Arctic Canada to restrict the hunting methods for polar bears. Examples of restrictions included: no killing bears in dens, no killing sows with cubs and designation of certain refuge areas. However, great flexibility was allowed for Inuit to take and participate in sponsoring trophy-hunting for polar bears by foreign hunters. Even though some people remain opposed to the killing of bears for any reason, not much widespread organised opposition to polar bear hunting has been mounted on a moral basis so far. The polar bear harvest is moderate annually worldwide, and the hunt is virtually impossible to observe by opponents of hunting or by the media. Polar bear tag allotments are issued to Inuit hunters, who have been harvesting bears annually for over 4000 years, there is a strong record of sustainable use and, consequently, it is difficult for opposition groups to make claims that limited hunting is a major extinction threat to polar bears.

The management of polar bears in Canada, including the setting of hunting quotas (Table 6.5), is the responsibility of the provincial and territorial governments and the wildlife man-
Table 6.5 Harvest quotas for Nunavut (NU) and the Inuvialuit Settlement Region (ISR) and the numbers of polar bears killed in Canada from 2008/2009 to 2014/2015. These are all known human-caused mortalities, including subsistence kills, recreational kills, problem bear kills, illegal kills. There are no quotas for Manitoba, as polar bears are not hunted there. The quota represents the guaranteed harvest level established through agreement with the aboriginal people

\begin{tabular}{|c|r|l|l|}
\hline Management year & ISR & NU & Total for Canada \\
\hline 2008/9 quota & 103 & 458 & 667 \\
\hline Killed & 41 & 463 & 553 \\
\hline 2009/10 quota & 103 & 434 & 643 \\
\hline Killed & 20 & 418 & 501 \\
\hline 2010/11 quota & 103 & 442 & 651 \\
\hline Killed & 75 & 440 & 629 \\
\hline 2011/12 quota & 103 & 449 & 635 \\
\hline Killed & 81 & 460 & 643 \\
\hline 2012/13 quota & 103 & 453 & 639 \\
\hline Killed & 63 & 458 & 616 \\
\hline 2013/14 quota & 96 & 425 & 604 \\
\hline Killed & 53 & 398 & 540 \\
\hline 2014/15 quota & 96 & 474 & 650 \\
\hline Killed & 42 & 422 & 536 \\
\hline
\end{tabular}

Source: Adapted from Duerner et al. (2018)

agement boards, which have been set up under Aboriginal land claim agreements. The federal government of Canada provides national coordination and is the authority for international agreements (for example, Agreement on the Conservation of Polar Bears, CITES), national legislation (for example, Species at Risk Act, Wild Animal and Plant Protection and Regulation of International and Interprovincial Trade Act) and the protection of natural heritage (for example, National Parks, National Park Reserves). All the details of the process are provided in Dowsley (2009a, b) and Duerner et al. (2018).

It is important to recall that polar bear tag allocation is through the hunter/trapper organisations and that Inuit hunters decide how many bears from their annual regional allotments will be harvested by native hunters and how many will be allocated for sale to foreign recreational hunters: often around $15 \%$, but with variations by community. Most recreational hunters are from the USA, followed by substantial numbers from central European countries. Under this quota system, the same numbers of bears will be killed even if recreational hunting were reduced or eliminated. 
The highly desirable recreational hunting tags would simply be used by Inuit hunters for subsistence hunting to provide meat, recreational opportunities and furs for crafts. The quotas are determined by biologists, Inuit traditional ecological knowledge and with prudent oversight and recommendations from the Polar Bear Technical Working Group. Based on the 20042005 observations of Inuit hunters seeing higher numbers of polar bears, the Nunavut territorial government increased its annual hunting quotas by $29 \%$ to 518 tags, an increase of 115 bears, despite the concern of biologists that this was too many tags. However as the Inuit value the bears so highly and seek conservative harvests, there is substantial compromise and adjustment with input from authorities, and in this case a scaling back did occur after this season. There is often disagreement about whether polar bears are increasing or decreasing in numbers between the scientists, who suggest that because of climatic change the numbers are decreasing, and the Inuit, who see more bears around their communities and think that the bears are increasing in number (Tyrrell 2006). However, pressure to reduce hunting for reasons not supported by evidence could result in an undue reduction in the value of polar bear harvesting, which may result in a loss of local support for conservation measures, including polar bear quotas, which would erode rather than support the protection of the polar bear as a species (Dowsley 2009a, b).

Foote and Wenzel (2008) suggest there are three-way reciprocal benefits: hunters reap profound emotional and experiential benefits; hosting communities find value, both tangible and intangible, in the process of supporting hunting for species such as polar bear; and ecosystem robustness and sustainability are usually enhanced by increased value, resulting in higher conservation priority given to the habitats of hunted species. Importantly, these species, such as the polar bear, are accorded great intrinsic value and afforded protection resulting from conservation concepts being incorporated into carefully regulated hunting protocols. The hunting affects the way people value wildlife and wildlife habitat. Consequently, it can contribute to sus- tainability of hunted wildlife populations and their habitat by providing the incentive for local people living in close contact with wildlife species to become their stewards, as the Inuit have always been for the last 4000 years.

The causal chain of reduced ice/nutritionally stressed polar bears/more conflicts with people is supported by considerable empirical evidence from studies in diverse locations. The nature of this relationship is also something on which scientists and northern indigenous people largely agree (Lemelin et al. 2010). This congruence is important because effective management of polar bears requires cooperation between those groups, and, to date, such agreement has been scarce.

In 2008 the US Endangered Species Act listed polar bears as threatened, and commercial imports of bear parts into the USA were prohibited (see Freeman and Foote (2009) for the Inuit side of the argument). The effects of this change can be seen from 2006 figures, when 153 bears were taken by trophy hunters, and 2010/2011 when there were just twenty-six. In 2015 a CITES committee meeting in Tel Aviv determined that the international trade in polar bear is not detrimental to the survival of the species and the USA dropped a bid to ban the international trade in polar bear products. The US Fish and Wildlife Service decided not to pursue this at the CITES COP17 meeting in South Africa in 2016.

However, trophy hunters preferentially select the largest adults if they get the opportunity, and these genetically may be the individuals that are best able to sustain population numbers. The biased removal of big males as a result of hunting management that selects for them may have serious longer-term consequences for the genetic vigour of the population. The usual attempts to beat the Safari Club International Trophy Records, the annual World Hunting Awards, which recognises all hunters who have achieved exceptional levels of big game hunting, and the Pope and Young Record Book, which claims to be one of North America's leading bow-hunting and conservation organisations, do not help here. Some biologists have suggested that polar bears are inherently unsuitable as a target for recreational hunting as the population relies on high 
adult survival, has a low birth rate, high cub mortality, inhabits a marginal environment and is extremely vulnerable to the effects of habitat degradation and loss triggered by climate change, shipping developments and pollution as it is the top predator in the food chain. It also appears that some polar bear scientists have lost confidence in Canada's management of the polar bear hunt (Vongraven 2009; Peacock et al. 2011).

\subsubsection{Polar Bear Viewing}

Most ecotourists on polar bear viewing trips arrive in the Arctic, more particularly in staging areas where polar bears concentrate, with expectations of safely observing the bears. Quite reasonably, tour members expect to have heated lodging and prepared meals. This experience requires substantial infrastructure to isolate them from the bears (for example, elevated tour buses, gated observation decks and secure lodging). Such experiences are inherently social and group activities since viewing buggies are designed for ten to fifty people and tour boats may accommodate over 100 people per voyage.

The experience of polar bear viewing is simultaneously voyeuristic and vicarious in that participants pay to be in the proximity of bears for viewing while also paying to be isolated from the field conditions and the ways of life that actually constitute the bears' environment. Problematically, there is little about polar bear viewing tours that reflect the living conditions of indigenous people, or the relationship they have with polar bears. Tour operators recognise and respond to their clients' demand for comfort, safety and gourmet meals. Luxury accommodation set in one of the harshest climates on earth holds a curious attraction for foreign visitors. Most tourism companies in Churchill (Manitoba), where a lot of the polar bear viewing takes place, work to minimise their ecological impacts and to avoid wildlife disturbance, yet perverse incentives exist to accommodate visitor desires, sometimes to the detriment of the resource. Isaacs (2000) observes that 'The rigors of a market system that caters to the resource-intensive preferences of modern con- sumers will make it difficult for low-impact ecotourism operators to prosper.' Amongst the advertisements for polar-bear-watching ecotourism, there seems no evidence or suggestion that any of the polar bear viewing ecotourism companies are Inuit-owned, and because almost all tourist needs are met by non-Inuit ecotour companies, the local people are likely to receive a reduced share of profits flowing from bear viewers. The provision of financial benefits to local indigenous people should be one of the primary criteria defining ecotourism. Bear viewing may be more accurately characterised as simply tourism, though, because there are no accepted standards or certifying organisations, the term 'ecotour' will probably continue to be used in advertising this activity.

Churchill, on the south shore of Hudson Bay, is world-famous for its polar bear viewing activities using tundra vehicles (TVs), and there is a statue of a polar bear in the town, emphasising its importance to the region (Fig. 6.7). The first company started tours in 1974, with other companies following in the early 1980s (Webb 1985). The Gordon Point area, which is predominantly used for polar bear viewing, is located along the westcentral part of the point during the ice-free period (July to November), when the bears are forced to come ashore (Stirling et al. 1977). While ashore, bears conserve energy and are sustained by their stored fat reserves. Tour operators have been transporting visitors into areas where bears congregate, using large customised vehicles that travel across tundra. Human-TV-polar bear interactions have been observed in these staging areas, resulting in some instances of food conditioning (where food is given to bears so that they get used to this and are conditioned), habituation and harassment (Watts and Ratson 1989; Herrero and Herrero 1997). Some of these interactions may elicit behavioural and physiological responses that could compromise the bears' energy balance (Knight and Gutzwiller 1995). TV activity may impose an energetic cost on bears, depriving them of energy that could otherwise be utilised for growth, maintenance, reproduction and lactation, or for different activities such as male play-fighting (Dyck 2001). Polar bears are easily affected 


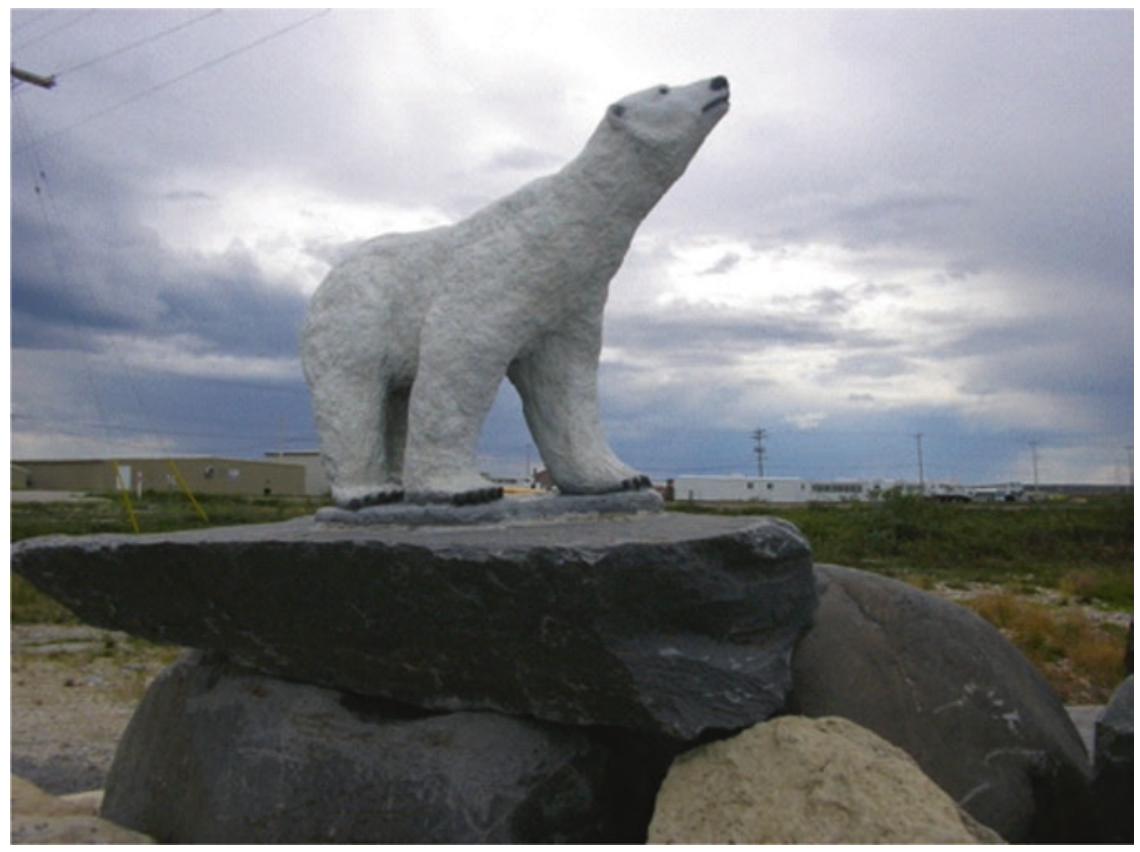

Fig. 6.7 Polar bear statue in Churchill, Manitoba. (Photo: (WT-en) Heyrenee)

by hyperthermia, and so reduction of unnecessary movement may be important for the conservation of energy. The rate of depletion of energy reserves will influence an animal's condition when it returns to the sea ice and may affect reproductive success, or even subsequent survival. Churchill is unique in that bears are viewed at close distances relative to any other bear-viewing location. The close proximity of TVs and polar bears in the Gordon Point area at Churchill poses a question vital to the bear management and the nature tourism industry: do human activities at Churchill induce behavioural changes in polar bears? In addition to viewing bears from TVs, two stationary tundra train lodges provide accommodation and viewing options. The vehicles are large, with the base of the viewing windows reaching approximately $3.5 \mathrm{~m}$ off the ground, and the lodges are modifications of these vehicles, with seven vehicles linked together making a combined length of approximately $60 \mathrm{~m}$.

TVs use a trail system consisting of established trails, eskers and foreshore flats to transport visitors into the Gordon Point area. While most visitors engage in bear-viewing activities from TVs, many take advantage of helicopter rides. These flights usually begin in July and last as long as bears are in the area. Half-hour and hour-long tours are flown along the shoreline, over spits, Fox Island and toward Cape Churchill. Most of these activities take place in the Churchill Wildlife Management Area and are thus overseen by Manitoba Conservation. Permits are issued for TVs, train lodges and helicopter activities and also include a provision for vehicles to drive on established trails. However, no special training or ecological educational background is required to operate TVs. Manitoba Conservation set certain spits and islands aside as Designated Polar Bear Resting areas to provide undisturbed resting opportunities for polar bears awaiting the freezeup of Hudson Bay. The primary polar bear viewing season at Churchill lasts only forty-two to fifty days on average, but it is the number of tourists involved and the types of interactions with the bears that cause the problems. In 2000 an estimate of 9720 tourists was made by Dyck (2001), but on the basis of information provided by him this was a gross underestimate and CBS News in 2004 suggested that there were 15,000 tourists travelling to Churchill, although some visit for other reasons, such as to see beluga whales. 
The mean approach distance between bears and vehicles was estimated by Dyck (2001) to be $24.3 \mathrm{~m}$. The observed average number of TVs around a bear was $2.1+/-0.1 \mathrm{TV}$, ranging from one to nine TVs. The minimum time TVs were within 20-30 m of a bear was estimated to be three hours. Family groups $(5.5+/-1.2 \mathrm{TVs})$ and sub-adult males $(4.6+/-1.2)$ had more TVs around them than bears of other sex and age classes. Disturbances in the form of approaching and leaving TVs around a bear occurred every $10.2+/-1.7$ minutes. Vigilance behaviour in the presence of TV activity was significantly increased, with increased frequencies of head-ups, and decreased time intervals between vigilance bouts (Dyck and Baydack 2004). Overall, bears were 2.5 times more vigilant in the presence of TVs than without. Qualitative information was recorded by Dyck (2001) on tourist behaviour, helicopter and TV activity during polar bear viewing. On several occasions, passengers on TVs were observed photographing polar bears from the roofs of vehicles. Film crews and regular passengers were observed disembarking from TVs for unknown purposes, but it is assumed for better photo opportunities of specific objects of interest, likely to be bears.

On the back deck of the TVs some passengers were noisy in close proximity to lying bears (yelling, talking loudly, laughing), and some were banging on the outside of the deck to get the viewed bear's attention as the windows can be put down. Passengers also leaned over the railing of the deck when the vehicle was stationary. Attempts to get the attention of polar bears included whistling and loud talking by passengers, and the starting of the engine by TV drivers. When light conditions were not favourable for photography, pictures were taken with flash-supported cameras at relatively short distances to bears (for example, when a bear was rearing up on the TV).

It was observed on three occasions that helicopter bear-viewing tours flew over Designated Polar Bear Resting Areas and landed, with passengers disembarking. Helicopters landed throughout the Gordon Point area to pick up and drop off passengers. There were at least two instances observed where helicopters displaced bears to allow closer landing to a TV.
Displacement was achieved by hovering low (under $50 \mathrm{~m}$ ) and next to the bear, which resulted in the bear moving farther away from the TV.

TVs used any trail that remotely resembled an all-weather road or existing trail, including snowmobile and ATV trails. Increased speeds were noticed when tundra vehicles were returning to base and the day trips were finished. It was also observed on several occasions that family groups were approached in areas with no existing trail system. These family groups were pursued for up to $4 \mathrm{~km}$ and for between two and four hours to allow professional photographers and film crews unique photo opportunities.

Based on the results of Dyck's (2001) research, the main recommendations were: Manitoba Conservation should seek dialogue with stakeholders to develop a protocol for consistent and predictable TV and helicopter activities; Manitoba Conservation should encourage more research examining the polar bear viewing industry; viewing distances of at least $20 \mathrm{~m}$ should be maintained; TV movement around bears should be minimised; passengers on vehicles should avoid noisy behaviour; bears should not be pursued during viewing activities. However, Eckhardt (2005) stated that bears that responded to vehicle approach did so at an average of $43 \mathrm{~m}$, and this was closer than $50 \mathrm{~m}$, which is often suggested as a possible buffer zone distance and is the distance between wildlife and tourists recommended to minimise response. This is a much greater distance than that suggested by Dyck (2001). This greater distance from bears to tourist vehicles could minimise responses to vehicles and reduce behavioural responses in the number of bears in response to vehicle approach.

The question is not how to manage bears, but rather how to design management actions that allow polar bear viewing that minimises the effect on bears. Hence, management actions (for example, education for tourists and tour operators, policies) should be designed that manage human activity in this area. Cooperation among all parties (for example, Manitoba Conservation, Manitoba Department of Culture, Heritage and Tourism, tour operators, Parks Canada) is necessary to accomplish this goal. In the year 2016- 
2017 there was a reduction in tourism to Churchill because the rail connection with Winnipeg had been broken and there had been an impasse over who would pay for the repairs. Up to this event there had been approximately 12,000 tourists in the six-week polar bear viewing period, but poor communications, with no roads, expensive air fares and infrequent rail services, has always been a problem for tourism in Churchill.

It is misleading to characterise hunting as consumptive use and viewing-only tours as non-consumptive use. Both activities are likely to have demographic and survival costs to sub-populations of polar bears. Behavioural research has shown enhanced vigilance of polar bears in the presence of bear-watching tour buses, possibly increasing basal metabolic demands during this fasting period (Dyck and Baydack 2004). Less scrupulous tour operators have disturbed bears in ways such as baiting bears into scenic or viewable settings (Herrero and Herrero 1997), and some have been reputed to smear the wheels or exhausts of their TVs with rotten meat or fish to guarantee their clients a close encounter with a polar bear.

The town of Churchill expands from a base population of 900 to several thousand people during the viewing season, and there is always the risk of human-bear conflicts. There is a welldeveloped bear alert system in place and a bear compound and a system to helicopter bears away from Churchill. Bears may escape people if they choose to use other parts of the $150 \mathrm{~km}$ of undisturbed coastline along the western Hudson Bay instead of the $10 \mathrm{~km}$ accessible to bear-watching tours. Simply because there may be some costs to the bears does not mean bear-watching is not a worthwhile activity. Of possible political and conservation benefit, Lemelin and Wiersma (2005) found that bear-watchers self-reported that they had gained appreciation and introspection that would lead to a greater commitment to aiding the future well-being of polar bears and greater environmental stewardship.

Habituation and food conditioning both appear to be important behavioural factors leading individual polar bears into conflicts with people, as they are for other bear species (Herrero 2002; Herrero et al. 2005; Hopkins et al. 2010).
Evidence for this comes largely from Churchill, where for decades polar bears have had access to anthropogenic food sources such as rubbish dumps, deliberately placed baits and community refuse (Watts and Ratson 1989; Herrero and Herrero 1997). Lunn and Stirling (1985) found that tagged polar bears that had fed in the Churchill rubbish dump were significantly more likely to be destroyed as problem bears than tagged bears which had not fed there. They also found that tagged bears that had fed in that dump were twice as likely to be harvested by Inuit hunters from communities north of Churchill. This problem has now been reduced since the town rubbish dump has been closed since 2005 . Recently, Inuit and Cree communities have reported increases in polar bear-human interactions and conflicts around Baffin Bay and Hudson Bay, as well as bears being more aggressive and less afraid of people (Dowsley and Wenzel 2009; Nirlungayuk and Lee 2009; Tyrrell 2009; Lemelin et al. 2010). In western Hudson Bay, Inuit community members attribute these observed behavioural changes to long exposure of polar bears to people and anthropogenic foods in the Churchill region (Nirlungayuk and Lee 2009; Tyrrell 2009).

A reflection of the lack of research into the impacts of recreation on polar bears was the presentation by Fortin from the University of Montana at the 18th Meeting of the Polar Bear Specialist Group in 2016 on a survey intended to examine the potential for conflict between human recreation activities and polar bears throughout their range (Duerner et al. 2018).

\subsubsection{Musk Oxen: Giardia in Musk Oxen on Banks Island}

Whilst we have seen that recreational hunting of musk oxen has declined in the Canadian Arctic, it is still on offer as one of the iconic Arctic species for trophy hunters, and we have seen that in south-west Greenland there is a successful business too around Kangerlussuaq (Fig. 6.5). The International Union for Conservation of Nature (IUCN) list the numbers of musk oxen at around 121,000 in Canada, but in the Arctic archipelago 
these are declining as a result of lungworm which is a parasite, because of a bacteria, Erysipelothrix rhusiopathiae and/or because of a virus related to a similar one in domestic sheep and goats. It also appears that climate change may be making them more susceptible to illness (Bennett 2017).

Kutz et al. (2008) reported the discovery of Giardia duodenalis Assemblage A in musk oxen (Ovibos moschatus) on Banks Island, a remote region of the Canadian Arctic, and discussed the possible flow of this parasite in this ecosystem. The permanent human population of approximately 120 is restricted to the community of Sachs Harbour on the south-west coast. There is limited tourism, with fewer than 100 visitors to the island annually. Mammalian biodiversity is low, comprising approximately 50,000 musk oxen, 1100 Peary caribou, numerous arctic hares, arctic fox and brown and collared lemmings, polar bears and the occasional grizzly bear.

Giardia was found in seventy samples of musk ox faeces. As musk oxen were extremely rare on the island in the early twentieth century, the present infection is likely to result from recent, and perhaps ongoing, introduction(s) of Giardia associated with contemporary settlement and/or tourism. The high prevalence and intensity of Giardia observed in musk oxen in this study are unprecedented among wild ungulates and suggest that musk oxen are important hosts on Banks Island. Several characteristics of musk oxen and Giardia may support parasite maintenance. Musk oxen are highly susceptible and competent hosts for pathogens from many species. They are relatively sedentary herd animals that congregate in river valleys for feeding, a behavioural trait that contributes to large numbers of cysts in a moist environment and ongoing parasite exposure. Giardia cysts are cold-tolerant, immediately infective and few are needed to establish infection. Thus, musk oxen may now maintain Giardia Assemblage A in the absence of reservoir hosts or ongoing introductions and may serve as a source for infection for other species. Untyped Giardia species previously reported in Peary caribou on Banks Island may represent overspill from musk oxen. Behaviour of people and musk oxen also affords several opportunities for ongoing transmission between these hosts and between terrestrial and marine systems. In summer, spatial overlap between residents of Sachs Harbour, tourists and musk oxen is common, as all tend to concentrate around major water bodies. High abundance of Giardia infection in the large musk ox population results in significant contamination of water bodies and, because latrines are rare in this vast landscape, contamination of the land and water bodies with human faeces is likely. Residents and tourists often drink untreated water directly from these water bodies. Human sewage from Sachs Harbour, deposited untreated in a sewage pond accessible to wildlife, provides ongoing opportunities for parasite dispersal, as do the commercial musk ox harvests that are held almost every winter near the community. People working at these harvests may be directly exposed to cysts in the offal. Additionally, for many years this offal was disposed of untreated on the land near the temporary abattoirs used for the harvests, and more recently has been deposited on the sea ice. These disposal practices may provide a source of infection for people and terrestrial and marine wildlife. So we can see here that there may be links between climate change and diseases in large terrestrial mammals, and there could be links with either native human populations and/or tourists. However, further research is needed to establish the role of tourists, if any, in this dispersal process.

\subsection{Marine Mammals and the Potential Effects of Adventure Tourism}

The International Association of Antarctica Tour Operators (IAATO) indicates that the guidelines created for tour operators and visitors involved in bird- and marine wildlife-watching are intended to prevent the following from occurring: 'displacement from important feeding areas, disruption from feeding, disruption of reproductive and other social behaviours, changes to regular migratory pathways to avoid human interaction zones, injury, increased mortality or decreased productivity leading to population decline' (IAATO, n.d.). In an ideal world this would happen but it is 
necessary to see some of the potential conflicts that could occur with Adventure Tourism.

\subsubsection{Beluga Whales (Delphinapterus leucas)}

Each spring and autumn, the largest population of beluga whales (Delphinapterus leucas) in the world migrates along Manitoba's coast (Fig. 6.8.). This migration is interrupted during the summer months to feed, give birth and nurse young in Manitoba's northern river estuaries. In association with the annual beluga migration, a thriving whale-watching industry has also developed a strong presence in northern Manitoba. We need to identify if there are any actual or potential problems associated with this industry.

Beluga has always been an important resource for peoples living in northern Manitoba. Historically, Inuit, Cree and Dene hunted beluga as a food source. The outer skin and fat layer provided a source of vitamins and energy in the form of 'maqtaak'. The nutrient-rich meat was also eaten by people and was an important food source for sled dogs. Present-day subsistence harvests by Inuit continue in some areas of Nunavut and northern Manitoba (north of Churchill), but it is no longer a current practice by First Nations in Manitoba. The presence of large numbers of beluga also contributed to the development of a commercial whaling from the late $1800 \mathrm{~s}$ in Churchill and York Factory. Churchill was the

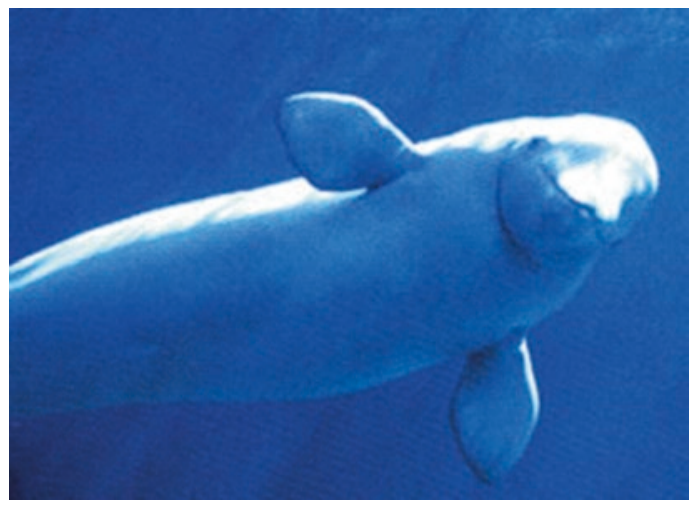

Fig. 6.8 Beluga whale. (Photo: Marine Mammal Commission, NOAA) most active site for this industry. Various companies operated up until 1968, when the whale-processing factory closed in Churchill. A small operation that captured live belugas for aquarium display operated in Churchill from 1967 to 1992.

Commercial and subsistence whaling and live capture of belugas in Churchill have now been replaced by ecotourism. This is an opportunity for visitors to experience large numbers of beluga as they go about their summer activities in the estuaries. The Churchill and Seal River estuaries, which harbour thousands of belugas in summer months, are the primary areas for beluga-watching. This includes guided boats, zodiac, kayak and snorkelling tours or simple shore observations of belugas from Cape Merry or Fort Prince of Whales. The beluga-related tourism industry in northern Manitoba is estimated at C\$5.6 million annually between 15 June and 30 August. It is expected to continue growing, as will the public's desire to observe beluga. The accessibility of belugas in summer, and polar bears in the autumn, has led to northern Manitoba becoming as a renowned destination for Arctic safaris.

The belugas that visit northern Manitoba's shores and estuaries in early summer are part of the Western Hudson Bay population. In late summer and autumn, these belugas extend their range further north to the shores of Kivalliq region of Nunavut, and to Ontario and Quebec, and to a lesser extent to the centre of Hudson Bay. By late September, few belugas remain along the coast of Manitoba. Their return migration is not yet well understood, but herds have been seen in pack ice along coastal Manitoba in May and June. As soon as the fast ice in the Nelson, Churchill and Seal estuaries breaks up in early summer, belugas enter the estuaries in their thousands and occupy them in large numbers all summer.

Every day, pods of belugas move in and out of the estuaries with the tide. Some belugas also move back and forth between the Churchill and Seal estuaries (Richard 2005), while animals from the Nelson estuary appear to remain there most of the summer, some moving northward to the other areas only later in the summer.

The Western Hudson Bay or Manitoba summering population is very large (Richard 2005), with 
the number of belugas occupying the Churchill, Seal and Nelson estuaries and surrounding offshore in late July and early August 2004 estimated at about 57,000 (Richard 2005). However, it could range between 41,000 and 91,000 belugas because of counting difficulties (Manitoba Western Hudson Bay Ad Hoc Beluga Habitat Sustainability Plan Committee 2016). Nevertheless, despite that imprecision, these results indicate that it is the largest population of belugas in the world.

Whilst it has been shown that boat traffic can affect whales, as we will see later, tourism boat traffic in the Churchill and Seal River is not presently thought to have a significant impact on belugas, owing to the low level of such activity. Current beluga tourism operators have developed self-regulating rules of conduct that attempt to minimise disturbance. Any increase in the level of tourism boat activity should, however, be carefully considered. If these operations expanded so that the number of boats on the water at any given time encompassed a much larger portion of the estuary, or if the activities of additional vessels was uncoordinated and targeted the same beluga pods, such changes could have an impact on belugas occupying these estuaries, and ultimately on the tourism industry that relies on them.

Recreational vessels, including sea-doos (personal watercraft that uses impeller-driven water power) and port-related boat traffic, add to the overall traffic in the estuary but are not bound by any specific rules of conduct, as exercised by the tourism operators. Although the Churchill estuary is heavily used, most residents are sensitive to the well-being of belugas and exercise care when navigating in the water with them.

The potential for hull and propeller strikes is a particular concern with fast, small boats that can rapidly change their speed and course (including sea-doos), if these vessels are not mindful of belugas around them. The Department of Fisheries and Oceans' whale-watching guidelines applied in other regions suggest that boaters use a slow speed if within $400 \mathrm{~m}$ of whales and idle when they come within $100 \mathrm{~m}$ of them.

Beluga-watching tours have been offered on the Churchill and Seal estuaries for decades. Over time, some tour operators have developed an informal, self-regulating 'Code of Conduct' which includes many proactive measures to support thriving beluga whale populations in these estuaries. Some of the measures include reduced speed when manoeuvring around whales, 'sharing whales' by limiting the number of boats surrounding whale groups and taking turns when viewing. Some operators have also installed propeller guards to protect belugas from moving parts of the boat and work to dissuade tourists from physical contact with belugas.

However, there seems a possible conflict between the beluga whale tourist boat operators and the Department of Fisheries and Oceans (DFO), because recently in 2014 there was a DFO proposition to impose a maximum $50 \mathrm{~m}$ approach zone between a boat and the belugas, with apparently no consultation with the tour operators. This resulted in a detailed document from the Churchill Beluga Whale Tour Operators Association and the Town of Churchill (2015) suggesting that the belugas are thriving in these estuaries and that the belugas are habituated to the presence of tour operators activities (viewing from boats, snorkelling, kayaking) and that there is no apparent impact on their life processes. The document suggests that a maximum $50 \mathrm{~m}$ approach would be impossible to implement as the belugas are curious and approach the boats, rather than the other way round, and that the voluntary understanding of policies and protocols in place has worked well for decades. They point out many inconsistences in the new suggested regulations. The importance of the summer beluga viewing to the tourist industry in Churchill was emphasised (it constitutes $8.9 \%$ of the tourism base), and if these new DFO regulations were implemented it would destroy this industry. What is needed is more research on the possible recreational disturbance on the beluga populations, especially as it is known that both belugas and narwhals are sensitive to seismic noise and icebreakers (Cucknell et al. 2015), although there are clearly major differences in type of noise disturbance here.

Labrun and Debichi (2018) produced a detailed report that examines the suitability of Western Hudson Bay as a site for conservation and in particular a National Marine Conservation 
Area (NMCA). They suggest that the Government of Canada, represented by Parks Canada, should establish a NMCA by 2020, which would benefit the polar bear, beluga and shorebird populations and protect the well-being of the tourism industry and the local population in Churchill and its environs.

Tour operators are the primary contact for most of the public's experiences with belugas and have the opportunity to provide a lasting impression. Manitoba Conservation and Water Stewardship recommend continued development of interpretive programming with tourism operators to encourage interest in belugas and promote awareness of beluga and their habitat needs. Programme messages could include, but should not be limited to:

- the intrinsic value of belugas to the people of Manitoba;

- the role of the Manitoba estuaries in the beluga life cycle and other uses of the habitat; and

- the effects of climate change, pollution and household actions that could contribute to reduced populations.

Further south in the St Lawrence estuary beluga are chronically exposed to noise and disturbance from commercial shipping, recreational activities and an extensive marine mammal observation industry. The peak traffic here increased between 2003 and 2012 as a result of the development of newly established whalewatching companies in the upper estuary in some sectors of the beluga's critical habitat. This takes place in July and August, when the beluga give birth. An above-average number of dead calves was also observed in the period 2010-2012, and the population seems to be facing a decrease. This is thought to be due to a combination of the marine traffic, persistent organic pollutants and occasional toxic algal blooms (Lair 2013). Hence there seems to be a difference between the impacts of noise and disturbance caused by shipping on beluga populations in the estuaries in the Churchill area and in the St Lawrence, and there seems to be a need for more research into the effects of recreation on the beluga.

\subsubsection{Conflicts with Traditional Inuit Beluga Hunting and Adventure Tourism}

In the Beaufort Sea-Mackenzie Delta area there is a conflict in the area between Inuvialuit (Canadian Western Arctic Inuit) hunters of beluga whales and the nature-based tourism industry (Mathias and Fast 1998; Dressler et al. 2001). The conflict between Inuvialuit beluga hunters and tourists has been developing rapidly, with the growth of the number and type of tourists in the region. According to the figures of the Government of the North West Territory (GNWT), visitor arrivals in Inuvik increased more than seven-fold between 1987 and 1998 (Dressler 1999). Almost all of these tourists are interested in viewing wildlife, as well as in aboriginal culture, and some of them end up in sites where belugas are being hunted or butchered, often creating uncomfortable encounters for both parties (Fast et al. 1998).

The Inuvialuit see the development of smallscale, nature-based tourism as a means of acquiring cash to supplement hunting activities and to provide jobs. Cultural tourism and ecotourism are considered desirable, giving the Inuvialuit the opportunity to enter into low-capital entrepreneurial ventures that are potentially compatible with their culture and sensitive to the environment (Hinch and Butler 1996; Notzke 1999). However, there are potential conflicts with tourism, and, until recent years, the Inuvialuit were virtually powerless to resolve these conflicts. Starting in 1984, formal mechanisms became available for the Inuvialuit to achieve both their economic needs and social objectives. The Inuvialuit Final Agreement, signed in 1984, covers an area of 72,000 sq. $\mathrm{km}$ and includes the six communities of Inuvik, Aklavik, Tuktoyaktuk, Holman, Paulatuk and Sachs Harbour. Section 14 of the agreement provides the Inuvialuit with exclusive rights to hunt all marine mammals, establishes a co-management body for marine mammals and fish (the Fisheries Joint Management Committee, or FJMC) and gives the Inuvialuit the first priority for wildlife-related guiding, outfitting and other commercial activities (DIAND 1984). A second mechanism is 
Canada's 1997 Oceans Act. The Oceans Act addresses the integrated management of activities in coastal, marine and estuarine waters of Canada, and contains language that provides for the inclusion of 'bodies established under land claims agreements' and other stakeholders, specifically mentioning 'affected aboriginal organizations, coastal communities and other persons' (Section 31). The integrated management programme under the Oceans Act is designed to address multiple-use conflicts.

By far the largest numbers of tourists come into the region in the summer months. The main Inuvialuit wildlife harvests (the spring goose hunt and the midsummer beluga whale hunt) coincide with the peak period of tourist visiting.

As ecotourists, cultural tourists and hunters tend to congregate where beluga whales are, the probability of conflict increases. The Beaufort Sea Beluga Management Plan (BSBMP) tourism guidelines were established to minimise this potential conflict (FJMC 1994, 2013). The guidelines were drawn up by the FJMC, which is the main co-management body under the Inuvialuit Final Agreement, the Inuvialuit Game Council (IGC) and the local Hunters and Trappers Committees (HTCs). The tourism guidelines have specific clauses, such as those against the harassment of marine mammals that are enforceable under the Federal Fisheries Act, the National Parks Act and the Territorial Travel and Tourism Act and Regulations. The tourism guidelines have provisions to designate areas where tourism may take place, to require tour operators to obtain HTC and the camp owner's permission if they are to visit whale hunting camps, to establish tour lengths, to prohibit photographing and filming of certain hunting activities, to prohibit low-level flying over whales and whaling areas, to require tourists and tour operators to remove all refuse from activity sites and to leave cultural artefacts as they were found (FJMC 1998). In particular, the BSBMP has power to establish zoning, with one zone where subsistence activities take priority over water-based tourism. The tourism guidelines require aeroplanes to fly no lower than 2500 feet over any area designated as a subsistence zone, but such provisions are difficult to enforce. This appears to be the case for other provisions as well, and it is generally thought that the tourism guidelines have had limited success in achieving their goals.

A persistent problem for the Inuvialuit is the intrusive photographing of beluga butchering, the 'tourist gaze' and independent adventure tourist travelling by kayak to hunting areas. Elders mentioned that on nine occasions kayakers got close to the beluga whales while the hunt was on, and that they often arrived unannounced at whaling camps. The problems are intrusiveness, cultural misrepresentation and commodification. Four elders felt that under no circumstances should tourists be allowed into hunting camps, and many others held mixed feelings towards inviting tourists into their camps.

The unsuccessful integration of whale-watching and whaling camp visits with whale harvesting has also particular consequences for the nature-based tourism industry. Owing to the sensitive nature and politics involved in whalewatching, most tour operators mentioned they would not become involved in this activity. Accordingly, this segment of the nature-based tourism market has become increasingly marginalised. It is thought by some locals that tourism could harm the beluga whales, and they mentioned the noise of charter planes, the approach of the independent marine kayaker and the noise of outboard motors ('kickers'), which scared the whales out of the shallower waters (where hunting typically occurs) into deeper waters. One elder from Inuvik commented on changes in beluga behaviour as affected by boats: 'the beluga do run and they do stop and they seem to be disturbed.' Similarly, an Inuvialuit man from Aklavik mentioned that during weekends, when boat traffic was heavier owing to hunting, it was more difficult than usual to harvest whales; he thought that it was the noise of 'kickers' that disturbed the whales. Thus, hunting boats as well as tour boats may harass beluga.

There is also great concern over smaller local tour boats moving into the calving areas of the local beluga whale population. Similarly, lowlevel flight excursions have been known to harass beluga whales as well (Fast et al. 1998). Whether 
from a cruise ship or out of Inuvik or Tuktoyaktuk, it is the emergence of highly mobile transportation means (zodiacs, hovercraft, small aircraft and helicopters) that allows tourists to move even closer to the whales. Since the peak of the tourism season coincides with beluga calving, it is anticipated the tourists may now want to see birthing and rearing. It has been documented that if boats get too close, they can cause the separation of young beluga calves from their mother. When separated experimentally, calves may transfer their attachment to the side of a nearby ship, potentially not to return to their mother (Edington and Edington 1986). A study on the St Lawrence beluga whale population found that, when ecotourism boats interacted with beluga whales, the belugas would show subtle surface avoidance; feeding and travelling belugas would generally terminate and not resume their activity (Blane and Jackson 1994). Further north, Fraker et al. (1997) found that beluga whales congregating in estuarine areas react by avoiding boat and barge traffic within approximately $2.5 \mathrm{~km}$. They found that when boats passed beluga travel paths, this would hinder and then delay the passage of the whales for several hours. The same study found that aircraft flying at an altitude of less than $200 \mathrm{~m}$ caused beluga to panic into a random pattern characterised by thrashing and wheeling.

Effects of tourism on other animals have also been noted: for example, during the spring goose hunt, large flocks of geese have been scared off by low-flying charter planes and helicopters. Elders from Aklavik and Tuktoyaktuk claimed that noise from low-flying planes drove caribou into a running panic. Such occurrences were most evident on the Yukon North Slope and Herschel Island. Adventure travellers, generally with their own modes of transportation, were known to camp on the shore of Herschel Island and on the Tuktoyaktuk town coast, inadvertently disturbing nesting shorebirds. Significant disruption to shore-breeding birds by hikers and kayakers camping along the banks of the Firth River and Herschel Island has been reported by Talarico and Mossop (1988).

The results suggest this is a conflict between Inuvialuit lifestyles and values and the values and expectations of tourists.

\subsubsection{Human Impacts on Narwhal (Monodon monocerus)}

Narwhals are a migratory species consisting of three populations in Arctic waters, predominately in Canada and Greenland (Fig. 6.9). In 2008, the IUCN assessed the species as near-threatened, with an unknown global population trend, although the most recent global population estimates for narwhals is in excess of 100,000 animals, including at least 90,000 in the Baffin Bay population, 12,500 in the Northern Hudson Bay population and 6400 in the East Greenland population. Canada and Greenland are the only countries that currently allow hunting of narwhals by Canadian Inuit and Greenland hunters for subsistence purposes, and according to the available data, on average 979 narwhal were landed globally per year from 2007 to 2011 (less than $1 \%$ of the global population). Broken down by country, this is an average of 621 narwhals landed in Canada per year and an average of 358 narwhals landed in Greenland per year (Shadbolt et al. 2015).

The main anthropogenic threats to narwhals, beyond the effects of rapid climate change on sea-ice dynamics, include hunting, shipping, commercial fisheries, industrial development (i.e., oil and gas), tourism and noise disturbance from these activities (Shadbolt et al. 2015). Only Inuit are permitted to hunt narwhals, with community quotas ranging from 5 to 50 animals and harvest limits ranging from 25 to 130 animals (see Appendix D in Shadbolt et al. 2015).

Although tourism is mentioned as a threat to the narwhal, there seems virtually no research on the effects of adventure tourism on these populations apart from a discussion of the ethical issues by Buckley $(2005,2010)$. However, there are adventure tours advertised to northern Baffin Island close to Pond Inlet specifically to see narwhal where they migrate in summer to shallow water in some of the bays, and some tours even suggest that, if the opportunity arises, swimming with the narwhal using drysuits and snorkels can occur. Any impact from these tourists is difficult to gauge, but it must be limited because of the small numbers of people involved on each tour and per year, and it is never going to be anything 
Fig. 6.9 White whale and narwhal (bottom image). (Source: British Mammals by

A. Thorburn (1920))

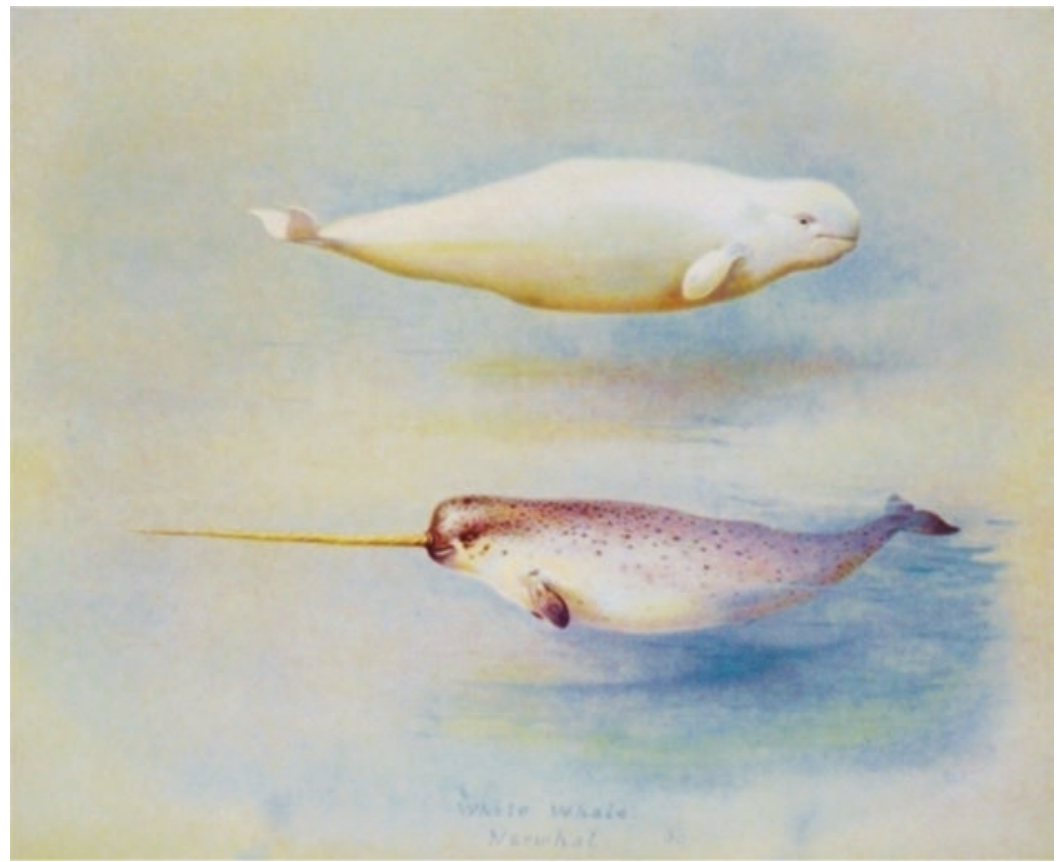

other than a specialised niche market because of the costs involved, not only in the adventure package itself but also the cost of charter flights from Ottawa to Pond Inlet.

\subsubsection{Impacts of Recreation on Harp Seals (Phoca groenlandica)}

Kovacs and Innes (1990) investigated the potential impacts of tourism viewing on harp seals and their pups in the Gulf of St Lawrence. The seals congregate in large groups on pack ice in late February/early March to give birth, nurse and mate. The seals' behaviour during and after visits by tourists was compared with behaviour observed at undisturbed sites by observers accompanying daily helicopter flights from a land base on Prince Edward Island. Virtually every aspect of the mothers' behaviour and of their pups was significantly affected by the presence of the tourists. The mothers' attendance was significantly reduced, and those that remained with their pups when tourists were present spent significantly more time alert and less time nursing their pups. Non-nursing social interactions occurred less frequently. Females with young pups were particularly aggressive and occasionally lashed out at their own pups, biting or clawing them when approached. Pups were more active when tourists were present, resting less and changing location more frequently. They also spent significantly more time alert and engaged in agonistic behaviour. When tourists approached to within $3 \mathrm{~m}$ or touched the pups, the pups frequently showed a freeze response that was only observed in this context. Pup age and tourist behaviour affected the degree of disturbance: for example, if there was a lot of tourist activity or loud noise a large area was disturbed. Tourist groups that made modest attempts to minimise disturbance, such as walking calmly or slowly into areas containing seals, had discernibly less impact. After the tourists left, most females returned to their pups promptly and behaviour characteristic of undisturbed situations usually resumed within one hour.

In the early part of the pupping the season separation and injury can be avoided by restricting access to the herd, prior to 1 March in most years, and by educating tourists in an appropriate protocol if a new-born pup and its mother are encountered. However, there appeared to be no evidence of abnormal abandonment or life-threatening 
Fig. 6.10 Ringed seal (Pusa hispida hispida) the smallest of the Arctic seals, which is common in Hudson Bay. (Source: NOAA Seal Survey, NOAA)

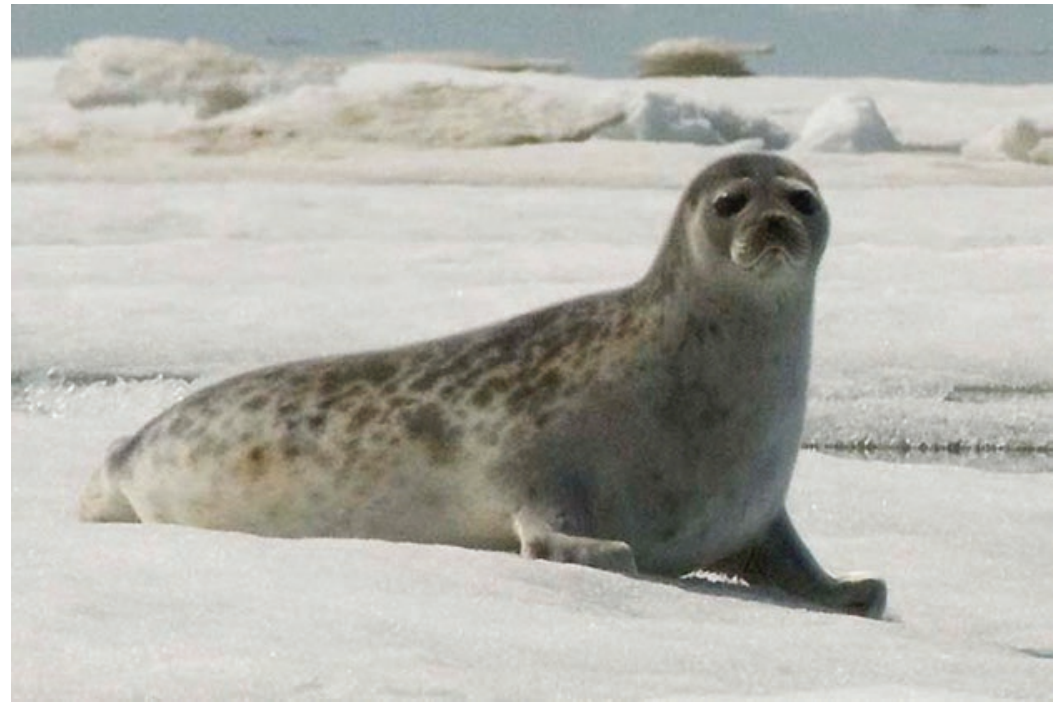

injury resulting from the tourists' visits. If some distance is maintained between tourists and the seal pups, then many mothers remain much calmer (a distance probably of $10 \mathrm{~m}$ seems best). If the tourists remain relatively quiet, move more slowly and crouch or remain seated, seal disturbance is greatly reduced. The tendency of most tourists was to move from pup to pup, which resulted in a very transient disturbance to individual seals. The results from this work showed that disturbance from tourists occurred, but at the level of tourism in the late 1980s this was not great, especially if education of the tourists and tour companies occurred regarding simple and fairly obvious behaviour protocols, such as minimum distance and no touching of the animals.

The effects of simple management of tourists is emphasised by the observations of Curtin et al. (2009) from a different part of the world, in south Devon, where they found that voluntary codes had reduced disturbance from operators but that there were still disturbances, mainly from private vessels. The results of the survey of tourists on the grey seal trips showed that they were aware of their potential impacts upon the wildlife, and were generally supportive of the voluntary codes in place. Therefore if an honest explanation and interpretation of the potential impacts of seal tourism are provided, it may encourage a protectionist predisposition in wildlife tourists and ren- der the compliance of voluntary codes a highly satisfactory tourist experience rather than a negative one. The same arguments related to management apply to a smaller Arctic seal common in Hudson Bay, the ringed seal (Pusa hispida hispida) (Fig. 6.10).

\subsubsection{Recreational Impacts on Birds}

The impact of noise on waterfowl from a tourism activity called 'flight-seeing' has been documented by Fishman (1994) for Parks Canada. He found that non-breeding birds appeared more sensitive to aircraft disturbance than nesting birds. Moulting birds were affected by helicopter disturbance at 100 to 750 feet, while resting snow geese were disturbed by a Cessna 185 at a minimum altitude of 300 feet; the effect was a reduction in flock sizes (Fishman 1994). Furthermore, Fishman found the impact of aircraft noise on caribou to be quite substantial. He explains that helicopter noise evokes a greater 'escape' from caribou than do fixed-wing aircraft However, both planes and helicopters affect caribou during calving and wintering periods, and it is cows and calves that are the most sensitive during these times (Fishman 1994).

Of additional concern is the disturbance of bird colonies by curious or unaware tourists. Many areas in the Arctic or Subarctic, such as Churchill 
in Manitoba, are already experiencing difficulties with tourists trampling nests hidden in the tundra. Bird-watchers have often trampled vegetation to such an extent that neighbouring birds leave their nests and abandon brood-rearing, often causing younger birds to die of starvation (Mieczkowski 1995; Edington and Edington 1986). For the Beaufort Delta region, it is particularly important that low-flying helicopters and cruise ships, as well as kayakers and canoeists, be prohibited close to all breeding areas. The sudden disturbance of shorebird colonies nesting on crags can cause their eggs to be knocked off as they fly off in panic (Edington and Edington 1986). The increased number of tourists to Herschel Island means that there are more threats to the important breeding bird communities as the main tourist arrivals tend to coincide with the latter stages of egg incubation and hatching (Talarico and Mossop 1998).

Environment Canada (2001) and the Canadian Wildlife Service (CWS) created a set of guidelines for seabird viewing by cruise ships:

- Helicopters can cause severe disturbance at seabird colonies and should not be used near nesting cliffs.

- Cruise ships should anchor well away from the breeding cliffs and the cliffs should be approached by zodiac only.

- Zodiac landings are discouraged.

- Zodiac visitation of bird cliffs should be limited to the morning and early afternoon (Murre chicks fledge in early August, primarily in the late afternoon and evening disturbance during peak fledging can cause premature fledging and consequently, high risk of mortality).

- Noise should be kept to a minimum during visits to the colony. Ship horns should not be blown and firearms should not be discharged in an attempt to cause a mass flight of adults from the colony. This causes heavy losses of eggs and chicks. (Adapted from Environment Canada and CWA (2001))

\subsection{Impacts on Terrestrial Vegetation}

Owing to a high preponderance of recreational vehicles (RVs) coming in off the Dempster highway, there is also potential for considerable impact on the Beaufort Delta's terrestrial environment. Much of the tundra vegetation found around tourism 'hot spots', such as in Tuktoyaktuk, is particularly vulnerable to damage from visitor trampling. As nature-based tourists embark on hikes from recreational campsites (where most RVs are stationed) or tour bases, they often follow the same path, eventually compacting plants and exposing soil to the sun and wind. Vegetative compaction by tents occurs at campsites, and at remote rural locations. Damage to tundra vegetation helps to accelerate erosion of the land, which is no longer protected from runoff, wind and sun. Erosion can result, with gully erosion increasing trail width and depth, the development of muddy stretches and the development of parallel trails, often considered as shortcuts ('informal trails'). The fragility of the tundra landscape is illustrated through the everlasting presence of cart tracks on Melville Island left in 1819 by a British expedition (Hampton and Cole 1988). This fragility was also illustrated by Forbes (1998) from close to Clyde River (Baffin Island), where the cumulative impacts resulting from single- and multi-pass vehicles tracks running perpendicular to a $3-4^{\circ}$ slope were noted. Changes could be induced by single passages of the tracked vehicle and the effects were persistent for twenty years. The effects of disturbance spread far from the point of the initial impact, even when there was just a single pass. The soil temperature regime and the plant nutrient regime were greatly altered from the initial vehicle disturbance and represented locally significant cumulative impacts. The general effect was to eliminate aquatics and stimulate the growth of lichens and shrubs. The vegetation could recover but not to the prior diversity levels and/or biomass.

The greatest concentration of vegetative trampling mentioned in Dressler (1999) was perceived to be upon and around the larger pingos (Fig. 6.11). Once the vegetative covering and 


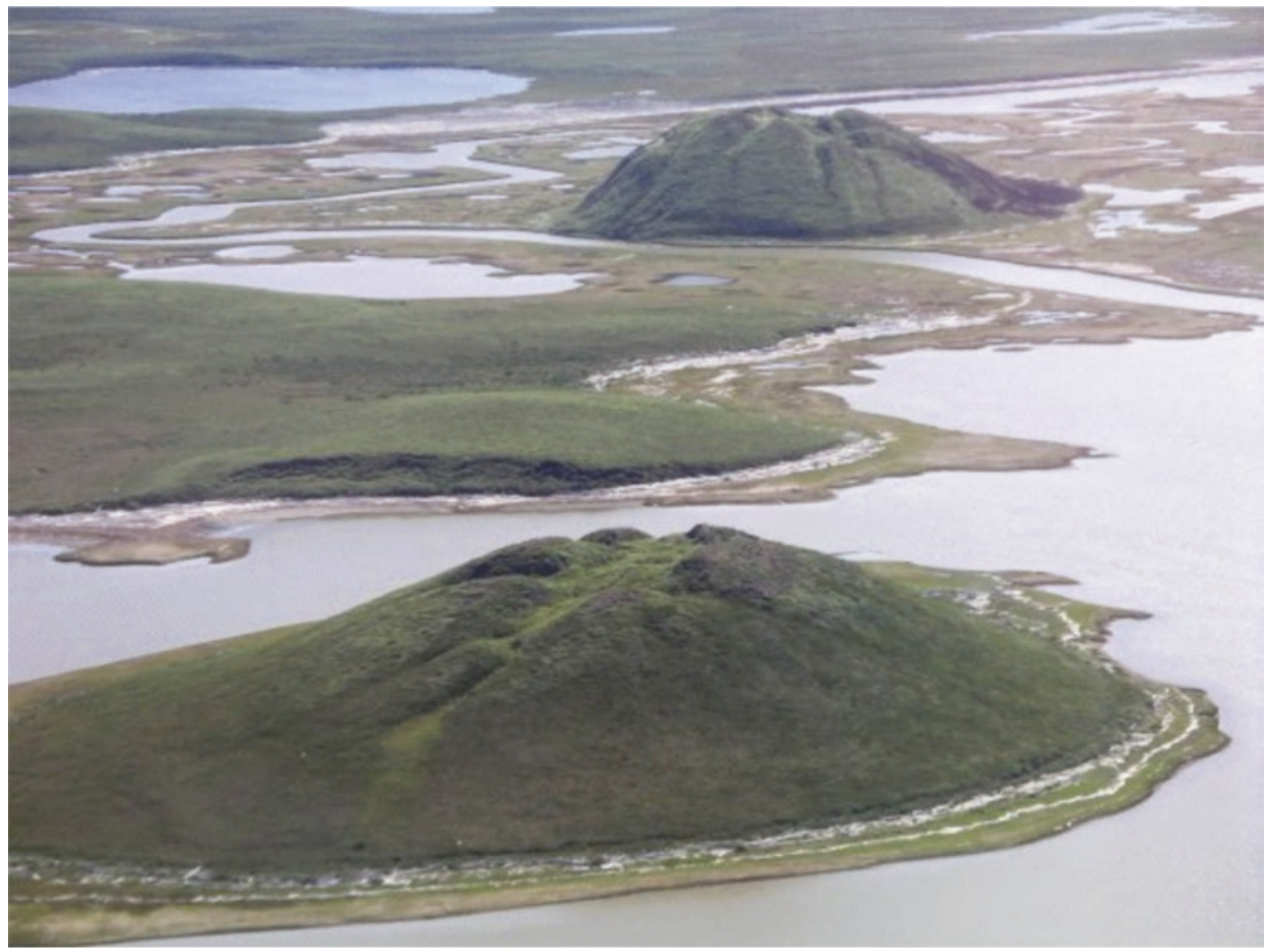

Fig. 6.11 Pingos near Tuktoyaktuk, North West Territories. (Photo: Emma Pike)

soils of a pingo are eroded, its core ice may be exposed to the sun and melt, and the structure decays. Local tours stemming out of Tuktoyaktuk and Inuvik, such as the 'Boat to the Pingos' tours, and resident use of the pingos are the most likely causes of this.

\subsection{Aboriginal (Indigenous) Tourism}

This branch of tourism refers to all tourism businesses majority owned, operated and/or controlled by First Nations, Metis or Inuit peoples that can demonstrate a connection and responsibility to the local aboriginal community and traditional territory where the operation resides (O'Neil et al. 2015).

Aboriginal cultural tourism meets the aboriginal tourism criteria, and in addition, a significant portion of the experience incorporates aboriginal culture in a manner that is appropriate, respectful and true to the aboriginal culture being portrayed. The authenticity is ensured through the active involvement of aboriginal people in the development and delivery of the experience. Overall for Canada the top aboriginal tourism sector is outdoor adventure, with $20.9 \%$ of the businesses, whilst in the far north this figure is $28 \%$ (O'Neil et al. 2015). The spotlight is on nature and landbased adventure, such as dog-sledding, fishing and hunting, which are all compatible with the lifestyle of the indigenous peoples. In the Yukon there are sixteen outdoor adventure businesses, the NWT have thirty-one and in Nunavut there are twelve. The outdoor and adventure services provided include:

- guided wildlife viewing and nature walks $63 \%$;

- guided fishing and hunting $22 \%$;

- guided trail rides and horseback excursions $13 \%$; and

- boat/canoe/kayak tours $40 \%$. 
Two examples of these aboriginal tourism activities from the far north can be given:

Bobby Drygeese is the owner-operator of B Dene Adventures, an outdoor cultural adventure company located in Dettah, which is $27 \mathrm{~km}$ by road from Yellowknife, NWT (which is $6.5 \mathrm{~km}$ by ice road in the winter). Since 2009, he has been sharing the Dene culture with visitors at his bush camp on the outskirts of Dettah. The village's name means 'Burnt Point' in the Tli Cho language, which refers to a traditional fishing camp used by the Dene for hundreds of years. The site has been Bobby's family fishing and camping spot for several generations. With the advice and approval of his grandmother he was told what he could share, such as the Shovel and Giant Beaver stories, and what must remain sacred. Visitors are entertained by demonstrations, participate in hand games and fishing, and are educated on the history of the territory, including signing of Treaty 8 in 1899, prospector days and gold mines to the present day.

The tourist packages offered are:

- The Dene and Our Land - A Dene Cultural Experience which is a four-hour tour at the family fish/bush camp.

- Dene Cultural Tours, which are two-hour guided tours through three northern Dene communities in Yellowknife, Ndilo and Dettah, to learn of the Dene people's relationship with the land, their history and culture. Winter tours travel the ice road to Dettah.

- Winter Cultural Tours are a three-hour tour bringing visitors through Yellowknife by ice road to Ndilo and Dettah and then by snowmobile to B Dene camp, where they learn Dene history of the land, the Wiliideah people in tepees and see demonstrations of hand games. Under Dene Skies is a tour embracing aurora viewing and photographing the Northern Lights, learning Dene history, legends and stories, hearing drumming and sampling traditional foods. The Boat Tour is a two- to four-hour boat trip along the traditional route through Yellowknife Bay, Wool Bay and the inside passage.

In low season from September to June, B Dene Adventures is also part of the local aboriginal school programme. At the fish/bush camp, children learn from Bobby about Dene life, and how to play stick games and catch and process fish. Speciality camps are also available for all ages and are tailored to the group's interest. Activities are educational and/or focus on team building, and are interactive as day or overnight excursions. Camp topics can focus on: birds, berries and medicines, aboriginal awareness, winter survival, moose/caribou hide tanning, trapping and snaring, traditional Dene games, canoeing and fishing.

For Carcross/Tagish First Nation (CTFN), in the Yukon, the Inuvialuit Settlement Region agreement presented an opportunity for 'nation re-building' to fulfil their economic vision to build a private sector economy in Carcross that will create a sustainable flow of job and business opportunities for the community, the First Nation and the region.

CTFN's approach was the creation of an arm's-length development corporation called the Carcross Tagish Management Corporation (CTMC). Shortly afterwards a comprehensive community economic development plan was produced that incorporated their resources (people, land, natural resources, culture and heritage) whilst capitalising and developing the opportunities that were available to them via market forces. Community members were looking for industries that were environmentally friendly, which ruled out mining. Since mining was out, tourism became the key. To bring the economic vision to life, the community created a four-pillar strategy: grow a new niche market; service that new market; accommodate the new market; and create a year-round market.

Tourism is an important industry to Carcross and CTMC's economic strategy. More than 100,000 tourists pass through Carcross annually. However, for Tagish-Tlingit people, tourism pro- 
vides a means by which to preserve and protect their culture, language and way of life, re-establish their history into Yukon's history and, yet more important, connect their youth to their culture, heritage and lands. CTFN leadership understood this when they proposed the development of mountain bike trails led by youth as a way to redirect youth to a healthy way of life as well as establishing a carving centre to commission totem poles.

The bike trails became the pride of CTFN youth, and of the community and the Yukon. When CTFN achieved self-government, the first thing it did was prepare a full infrastructure and land management plan. Yet, in order for Carcross to capture a larger share of Yukon visitors and encourage them to extend their stay, CTFN had to develop a comprehensive plan consisting of practices, operating structure, systems, businesses and activities that would create the right environment to entice tourists to make longer visits, satisfy the concerns and interests of Carcross citizens and attract investors and partners. For the strategy to be successful, it was important that CTFN should have the active involvement of cruise ship companies and Carcross citizens, and strategies to achieve economic growth. CTMC realised the strategy needed to be focused on establishing destination products. This effort started with building mountain bike trails, opening a carving centre, Skookum Jim's museum and a new visitor information centre, and attracting many new entrepreneurs and partners to the town. Vital to all this was catering to the many existing tourists arriving from Skagway's cruise liners. Cruise ship companies control rail travel in the region and many tour packages that are offered to tourists, such as mountain bike or hiking trips. Whatever CTFN built had to meet their standards and fulfil needs identified by cruise ship companies, including any tour company partners, to encourage them to increase their customers' time in Carcross and promote other activities. CTFN listened to the community and tour companies. Consequently, CTFN's business corporation, Carcross Tagish Management Corporation (CTMC), established partnerships with Alaska Excursion and other specialist tour companies. These companies bring jeeps with mountain bikes to the community and shop in the Carcross Commons.
Carcross citizens' support was needed to ensure the plans ultimately benefited them while protecting their lifestyle and promoting TagishTlingit culture, values and beliefs. Above all, the plans had to enable the people to fulfil their cultural role as environmental stewards.

Community sessions were hosted to gather ideas and identify concerns, as well as map development and protected areas. The resulting strategy outlined a community vision that centred on building a strong economic core consisting of the downtown area, mountain bike trails, a resort, art gallery and accommodations. It also identified spin-off business opportunities for Carcross and new residents.

The development had four stages:

- target the niche markets 'Hikers, Bikers and (wind) Boards';

- service the niche markets with Carcross Commons retail village;

- pursue the accommodations market;

- build a year-round waterfront development.

Montana Mountain Trails fulfils the first target, 'Hikers, Bikers and Boarders', while the establishment of Carcross Commons is the second. CTFN is currently working on securing an investor to contribute to the $\mathrm{C} \$ 65$ million resort development, and the fourth stage of the year round development is planned, with the full funds raised.

The two main pillars to this plan are Montana Mountain Trails and Carcross Commons Retail Village. All biking and village activities emphasise the production of community benefits (jobs, training and entrepreneurship).

Essential to maintaining the cultural and environmental principles of CTFN is the Tourism Code of Conduct guide, which was developed in 2004 and instructs visitors on how to enjoy their experience in Carcross respectfully on the trails, in the community and on all traditional lands. The guide is 'an essential tool for sound management of tourism development that balances our economic agenda with social development, cultural preservation and environmental protection'. It is also the regulator that guides CTFN com- 
mercial operations and others' activities in their lands. It promotes the values of equality, learning and sharing, respect, integrity, quality service, sustainability and inclusivity, while emphasising the need to:

- respect the culture;

- protect the environment;

- enhance community benefits;

- support business development.

Montana Mountain Trails (www.montanamountain.ca) was an initiative designed with two purposes: to attract visitors, and to provide a way to involve youth. In 2006, with very little to do in the community outside their family, an increasing number of young people were turning to dangerous behaviour, such as alcohol, drugs and other activities. Community leaders wanted to reverse this trend by providing young people with something they could call their own.

Trails development was built by the Singletrack to Success (S2S) project with the support of the Government of Yukon Sport and Recreation Branch and Community Development Fund, the Canadian Northern Economic Development Agency and Tagish Lake Gold Corporation. The project started with fifteen youths aged fourteen or over working closely with community leaders. While carving trails, leaders taught them how to plan and build trails, identify plants, protect heritage sites, understand traditional place-names and have an appreciation of nature. Leadership was key, especially having the chief champion of the programme address some community members' concerns that the trails would harm the mountain, wildlife and natural environment, and that Tagish-Tlingit people would be barred from continuing outdoor and cultural activities. This was because many Carcross citizens still spend summers at family fishing camps. Concerns were addressed, and Montana Mountain Trails earned accolades from mountain bike enthusiasts worldwide. For example, it was selected by Outside Magazine as the 2013 'Global Mountain Bike Destination of the Year', awarded TourismYukon 'Innovator of the Year award', was one of five Tourism Industry
Association of Canada (TIAC) 'National Tourism Attractions' finalists and won the Mountain Equipment Coop (MEC) contest for 'East and West Canada Best: Dirt Search' by beating Whistler, Vancouver and Victoria.

Mountain Hero trail in Carcross, just outside Whitehorse, was granted epic status in 2011; the International Mountain Bike Association (IMBA) states that the Mountain Hero trail offers stunning alpine views, historic mining artefacts and a chance to see caribou and other wildlife (IMBA 2012). Rowsell and Maher (2017) discuss the attributes of the Yukon trails, mentioning their uniqueness in terms of their remoteness and also their scenery, with views of mountains and forests, and alpine riding above the treeline (Fig. 6.12). The trail builders have designed trails around historic landmarks (mining activities), scenic views and alpine areas to give a sense of remoteness very different from the experiences of the mountain bikers' home environment and to give a distinctive adventure tourism experience.

In the Carcross mountain biking developments, from the first bike specific trail created in 2004 there are now $3500-4000$ people visiting the 400 population settlement in the four- to five-month riding season (2013), with many from Alaska. As many old mining and forest trails were used as part of this development, the environmental effects were limited to the new trails that linked in with the old, and the trail maintenance appears good. There are now CTMC partnerships with niche tour companies Mountain Bike Tour Company, Boreale Mountain Biking and Cabin Fever Adventures, who also have also offices in Carcross. The trails are a point of pride for young people, who have taken ownership of the trails and proudly report 'I built those', and a film about this mountain bike project was shown at the Banff Mountain Film festival.

Overall in Canada, International Mountain Biking Association Canada was the driving force behind the vision to create a Trail Care Crew programme. This has been operating since 2010 and is a partnership between Parks Canada and IMBA Canada, with commercial support from various organisations, including Shimano. The goals have been to inspire high-quality trail projects and increase stewardship of Canada's public 


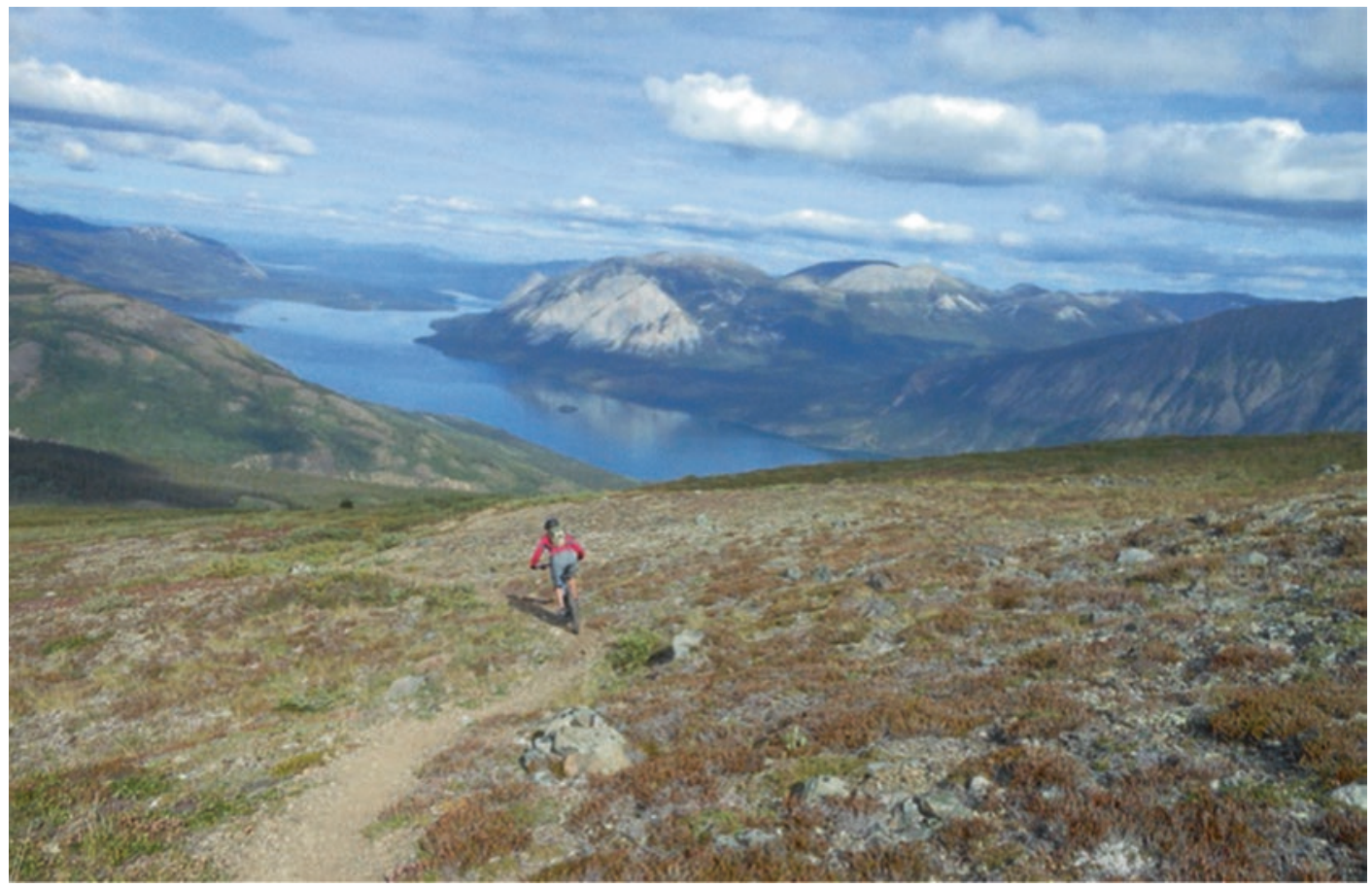

Fig. 6.12 The view from the top of Montana Mountain, Carcross, Yukon. (Source: Rowsell and Maher (2017))

lands by ensuring sustainable trail building and maintenance knowledge, by trail project evaluation and encouraging volunteering for maintenance. This has been carried out by IMBA Trail Building Schools and specialised workshops, which have trained local volunteer groups to work more effectively with land managers.

\subsection{Canadian Arctic Pleasure Craft Tourism}

Given the increasing possibilities for small pleasure craft tourism in the Canadian Arctic with climate change and change in sea ice conditions, it is no surprise that there has been a major growth in this adventure tourism sector in the last few years from 2010 onwards. The definition of pleasure craft at its broadest includes small vessel commercial tourism expeditions, commercial yacht charters and expeditions of privately owned sailing and motor boats, but it also includes sailing and rowing boats, pleasure craft and home-made boats not registered as commercial vessels.
The most comprehensive single source of information currently available to track pleasure craft vessel activity in Arctic Canada is the Canadian Coast Guard's NORDREG (Northern Canada vessel traffic monitoring services) annual dataset. Because smaller vessels are not required to report to NORDREG when operating in Canadian Arctic waters, the dataset cannot be considered completely accurate. However, given the navigational information provided freely by NORDREG to mariners in the region and the potential search-and-rescue benefits, many vessels do choose to report to the agency- and thus the data probably only slightly underestimate pleasure craft vessel activity. Figure 6.13 shows annually recorded pleasure vessel activity in Arctic Canada from 1990 to 2012 in the NORDREG dataset. For pleasure craft, a consistently low level of activity is apparent from 1990 through to 2008, with nine or fewer vessels appearing in the dataset annually and none in some years (Fig. 6.13). The following years show dramatic increases in pleasure craft activity, with the highest increases in 2011 and 2012 and a dou- 


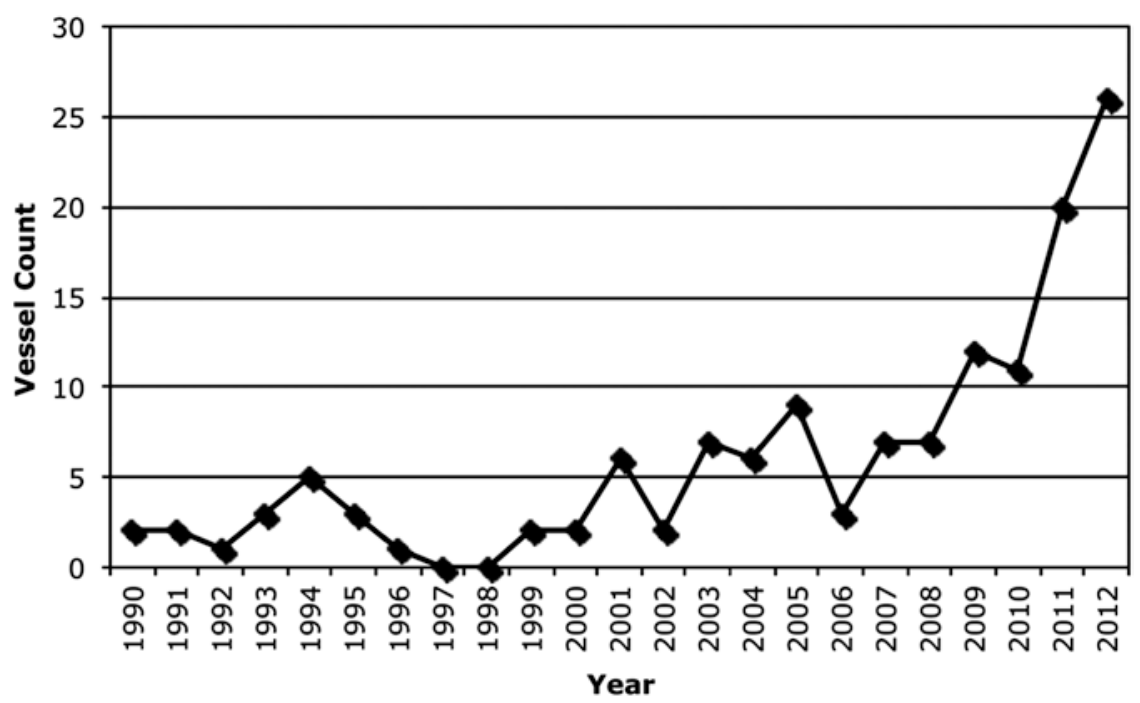

Fig. 6.13 Annual counts of recorded pleasure craft in the Canadian Arctic, 1990-2012. (Source: NORDREG Dataset (in Johnston et al. 2013))

bling from 2009 to 2012. Numbers are expected to continue to grow (Pizzolato et al. 2013).

These pleasure craft pose concerns for safety, cultural impacts, security and environmental sustainability related to interaction with the environment through inappropriate contact with wildlife - for example, by disturbing wildlife or chasing marine mammals-by dumping/discharge of waste in the ocean and through their relationship with national parks and other sensitive areas. (They might not have permits to enter, might not recognise park boundaries, there might be no signage indicating National Park, historic sites or other cultural sites and there might be no recognition or limited knowledge of guidelines or codes of conduct.) Marine expeditions, including yachts, could be vectors for the spread of invasive species, leading to biosecurity concerns (Hall et al. 2010).

\subsubsection{Management Concerns Regarding Pleasure Craft Travel in the Canadian Arctic as Identified by Survey of Interviewees}

There are many management concerns regarding pleasure craft tourism. These include:
- visitor safety system: limited search-and-rescue (SAR) infrastructure; high cost of SAR; unknown route plans; incomplete tacking of vessels; insufficient traffic for quick response; failure to report incidents;

- preparation of visitors: lack of knowledge about Arctic environment and limitations of infrastructure and services for Arctic marine travel; incomplete understanding of regulations and multi-party jurisdiction;

- lack of awareness of acceptable behaviour in communities and environment;

- lack of Arctic experience and ice navigation competence; inadequate insurance coverage;

- preparations of vessels; lack of appropriate equipment; non-ice-strengthened hulls;

- sovereignty: lack of domain awareness; incomplete reporting to authorities;

- a lack of mandatory mechanism to identify who is travelling and where they are planning to go; limited means of reinforcing sovereignty on water; minimal Government of Canada presence (limited Canadian Coast Guard vessel patrols);

- behaviour control, regulations, monitoring, enforcement; insufficient oversight opportunity; insufficient capacity to monitor and enforce regulations; some vessel regulations 
not applicable on private vessels (e.g., security);

- commercial vessels being reported or identified as private; no recognition by repeat visitors of changing rules over time.

There can be interaction with residents which can be negative for both, and also interaction with the environment and inappropriate contact with wildlife. Dumping or discharge of waste in the ocean can occur and there might be re-supply problems (such as fuel and food), with no re-supply being arranged in advance. There might be no established refuelling ports and no port facilities.

There could be issues related to National Parks and sensitive areas with no entry permit, no recognition of park boundaries, and there might not be any signage indicating where National Parks, historic sites, or other culturally significant locations are. Sometimes there is limited or no recognition or knowledge of guidelines. Opportunities to provide services and goods are not well understood: for example, services should not be provided free of charge. There can be no clear structure for supporting industry growth and development and no protocol for sharing information among agencies. There seems no way to channel inquiries from potential visitors and provide information about rules, regulations and travel in Arctic waters, and information is widely dispersed. There is limited understanding of vessel numbers and sector needs and a poor understanding of distinctions within the sector (type of vessel, size of vessel, nature of passengers), as well as inadequate response to diversification of market and the extent to which commercial vessels report as pleasure craft.

So there are multiple problems related to the development of the small-scale, pleasure craft industry. Other issues have emerged in recent years, including those related to national security and the protection of remote environments and Arctic wildlife. Earlier research on the expedition cruise ship industry in Arctic Canada revealed the need to examine management of the smaller pleasure craft vessels because of concerns about their impact on the environment and in regional communities (Stewart et al. 2012). Also, there are several known incidents involving yachts that have occurred, including illegal entry into Canada, transportation of illegal firearms, liquor and fireworks, disturbing wildlife and chasing Arctic marine mammals.

Johnston et al. (2013) included the following recommendations for management stakeholders:

\section{Management:}

- develop territorial and federal pleasure craft management plans;

- develop pleasure craft/yachting guidelines;

- establish site guidelines similar to Antarctica and Svalbard

(http://www.aeco.no/guidelines/siteguidelines/)

(www.ats.aq/e/ats_other_siteguidelines.htm);

- develop codes of conduct for pleasure craft travel (community visit, site visits, marine wildlife viewing).

\section{Research:}

- conduct a needs assessment of pleasure craft tourists;

- undertake a comprehensive data-gathering programme of vessels, including a provisional vessel count, to compare against existing NORDREG data;

- undertake studies of visitors, specifically in relation to knowledge gaps noted above.

\section{Information Provision:}

- examine the approach used by IAATO in providing information for yachts (http://iaato.org/ yachts);

- establish a pleasure craft information website using a one-window approach for all relevant information related to preparation, travel and regulation.

\section{Regulation}

- require all vessels to report to NORDREG;

- examine the policy context of private expeditions in the Antarctic for further regulatory development (guidelines for tourists including contingency plans, SAR, insurance and liability, environmental impact, permitting/ authorisation). 


\subsection{Canadian Arctic Cruise Tourism}

There is much less cruise ship tourism in Arctic Canada than in Greenland and Svalbard, even though the summer melting of sea ice has fuelled scenarios of an impending explosion in traffic in the Arctic, including cruise shipping in the region. However, although marine traffic in the Russian or Canadian Arctic seems to be definitely increasing, this is far from being an explosion. The number of cruise ships can be seen in Table 6.6.

Data is compiled from the Canadian Coast Guard, NORDREG, Iqaluit. 'Ships present' refers to the number of different cruise ships that appeared in the Canadian Arctic defined as the NORDREG zone. The 'Number of voyages' depicts their movements within the NORDREG zone: a voyage begins when a ship enters the NORDREG zone and ends when it exits. Thus, several cruises may take place within the same voyage in the sense NORDREG gives to this statistic. So, for example, the number of cruises documented in 2009 was 25, in 201024 and in 2011 18, whilst the figure for 2015 was 21 cruises.

In addition, although a few cargo voyages in the North West Passage have recently attracted a lot of media coverage, the increase is not in tran- sit traffic but rather in destination traffic, the growth being fuelled by vessels servicing local communities and natural resource exploitation activities. Similarly, it is unlikely that cruise tourism in the Canadian Arctic will experience the rapid growth predicted by some researchers and by the media. Most of the operators surveyed by Lasserre and Têtu (2015) communicated their lack of interest in expanding their business activities or in entering the Canadian cruise tourism market, with only three signalling their interest. Several underlined problems that appeared to them to hinder growth potential severely. Similarly, it is considered that a diversification of cruise itineraries and a modest increase in cruise tourism activities in the future are more realistic expectations, yet we might not witness the realisation of these expectations without significant development of marine infrastructures and a revision of regulations in the Canadian Arctic waters.

The patterns of cruise activity in all sub-regions of the Hudson Bay area during three cruise seasons (2006, 2008 and 2009) were analysed by Stewart and Dawson (2010) and Stewart et al. (2010) and mainly revealed a pattern of decline. Since the prevalence of sea ice is an important part of visitor experiences of polar cruises, the sea ice change and occurrence of icebergs in the Hudson Bay area was examined (Table 6.7), which suggested that the length of the navigable shipping season is increasing

Table 6.6 Number of cruise ships present in the Canadian Arctic

\begin{tabular}{|l|c|c|c|l|l|l|c|c|}
\hline Number of voyages & 2005 & 2006 & 2007 & 2008 & 2009 & 2010 & 2011 & 2012 \\
\hline Ships present & 6 & 9 & 9 & 11 & 7 & 11 & 6 & 7 \\
Voyages & 12 & 15 & 18 & 20 & 11 & 18 & 10 & 11 \\
\hline
\end{tabular}

Table 6.7 Iceberg counts from the Canadian Ice Service autumn survey (2000-2007)

\begin{tabular}{|l|l|l|l|}
\hline Year & Sub-region & Time period & Number of icebergs \\
\hline 2000 & Davis Strait/Hudson Strait & mid-October & 637 \\
2001 & Davis Strait/Hudson Strait & mid-October & 825 \\
2002 & Davis Strait/Hudson Strait & early October & 646 \\
\hline 2003 & Davis Strait/Hudson Strait & mid-/end October & 461 \\
\hline 2004 & Hudson Strait & mid-October & 451 \\
\hline 2005 & Davis Strait & mid-/end October & 262 \\
\hline 2006 & Davis Strait/Hudson Strait & early October & 309 \\
\hline 2007 & Davis Strait/Hudson Strait & mid-/end October & 178 \\
\hline 2008 & Davis Strait/Hudson Strait & early October & 217 \\
\hline
\end{tabular}

Source: Data from Stewart and Dawson (2010) and Stewart et al. (2010) 
in this region, which may facilitate both earlier and later shipping. However, in terms of cruise traffic, it was suggested that the demise of ice coverage signals a possible decline in cruise activity in most of the Hudson Bay area because ice-supported wildlife may shift north with the diminishing ice regime (Stewart and Dawson 2010; Stewart et al. 2010).

Currently there seems to be a balance of cruise activities throughout Arctic Canada, with all regions (apart from the ice-infested Queen Elizabeth Islands) experiencing some level of cruise activity. However, the analysis of cruise activity in the Hudson Bay region illustrates considerable variability and shows that a change in distribution of cruise activity may be under way. North West Passage tours are among the most popular expedition cruises in Arctic Canada because of the combination of good wildlife viewing opportunities, the spectacular scenery and unrivalled opportunities to witness the relics associated with the historical exploration of the route. The latest example is Hurtiguten's August 2020 cruise, involving full transit of the North West Passage by the new MS Roald Amundsen (launched in May 2019). This voyage will set off from Nome (Alaska) to Halifax (Nova Scotia) and call at sites such as Ulukhaktok, Cambridge Bay, Gjoa Haven, Fort Ross, Beechey Island, Dundar Harbour and Pond Inlet, including a crossing of the Davis Strait and sites in western Greenland. The Hudson Bay region currently struggles to compete with these destination characteristics and will continue to do so, particularly when the southern reaches of the Canadian Arctic transition faster to an ice-free summer. In the long term, the focus for cruise operators wishing to remain active in the Hudson Bay region, if market conditions allow it, may require a shift toward more land-based tourism activities, such as those related to arts and crafts and Inuit culture.

The estimated total number of cruise tourists in 2008, according to Maher (2012), was 112,891 for the Yukon, 2926 for Nunavut and only 364 for Nunatsiavut (Northern Labrador), whilst in 2015 cruise tourism for Nunavut was 2750, an increase from the 2011 figure of 1890.

Some of the environmental concerns include the dumping or discharge of waste into the ocean and oils spills, which could result from grounding of ships on poorly charted rocks or some other accident. For example, in 1996 the Hanseatic grounded in the Simpson Strait near the community of Gjoa Haven (Transportation Safety Board of Canada 1996), and the Clipper Adventurer was grounded in 2010 east of Kugluktuk in the Coronation Gulf (Stewart and Dawson 2010). The ships may have a problem with National Parks and other sensitive areas as they may not have permits which are required before any landing, they may not recognise where the park boundaries are, as there is no signage indicating a National Park, and they may have a limited knowledge of, or not recognise, guidelines. The potential disturbance effects of cruise tourism on wildlife have already been discussed in earlier sections of this chapter, and cultural conflicts and misunderstandings are possible too, as we have seen from the Yukon. There could be problems with visiting historic or cultural sites, as we have already seen in Svalbard, such as the ubiquitous footpath erosion or, much worse, the destruction of sites or the collection of artefacts or fossils.

\subsection{Maintenance of Archaeological Sites}

The maintenance of archaeological sites seemed to be an issue of great difficulty for some of the participants of Marquez's (2006) study. The desire to share archaeological finds with the tourists versus the need to protect a historically significant and often fragile site is the balance that the participants who work directly with the tourists struggle to achieve. Those who commented on the protection of these sensitive sites expressed a belief that 'it has to be one of those challenges that archaeological sites have to be maintained.' Many stakeholders understand the cultural value of the sites, and these remote archaeological sites are not only an incredible cultural resource but also a very strong indication of how long and how many people have been in the Arctic (Fig. 6.14). One participant noted the difficulty with choices when faced with 'the destruction or 


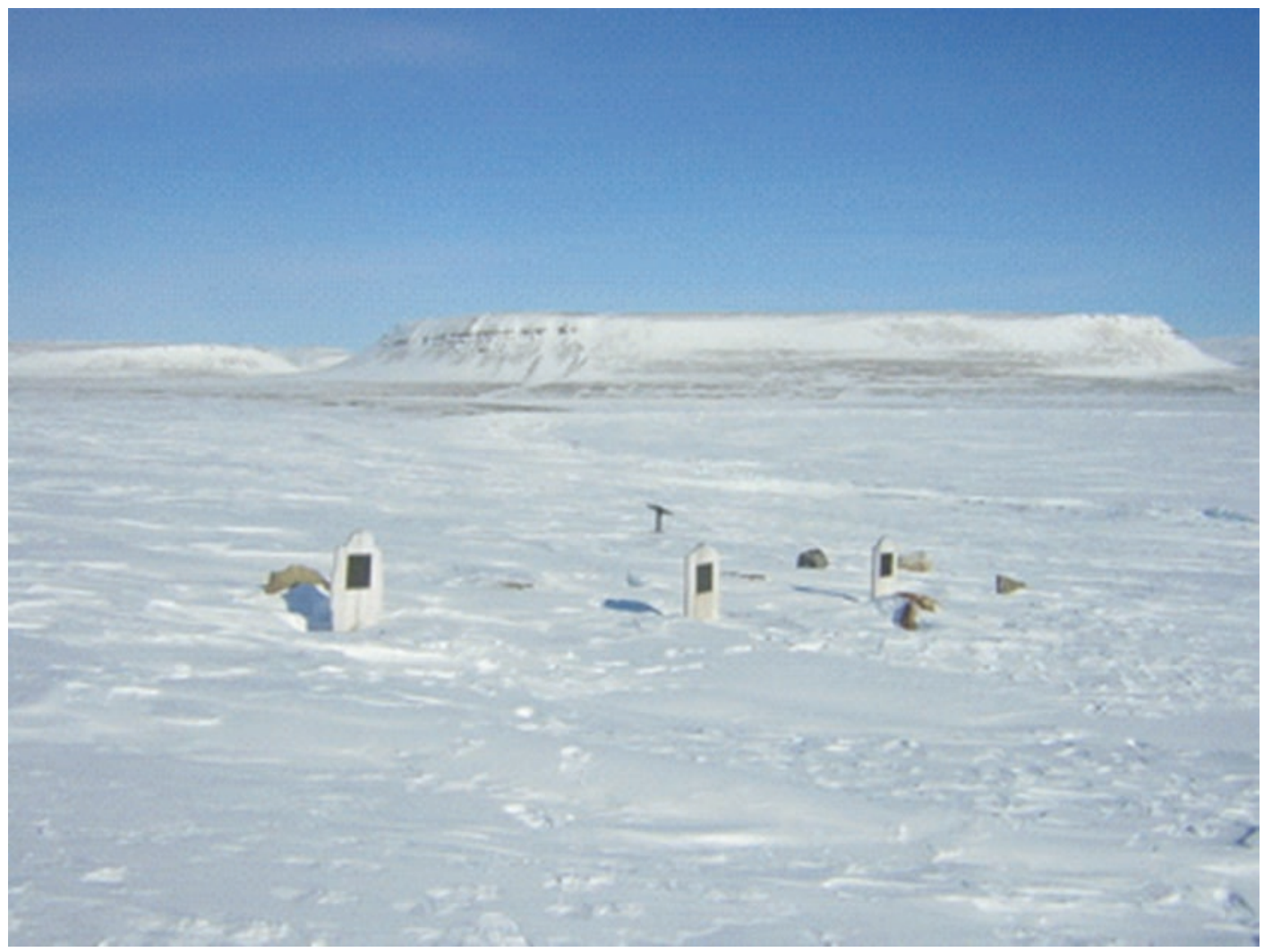

Fig. 6.14 Beechey Island graves of crewmen from the 1845 North West Passage expedition, led by Sir John Franklin. (Photo: Russell A. Potter, April 2004)

degradation of cultural and historic sites; you don't want to fence it off but it's a fine balance and sometimes you just have to ask yourself whether it is worthwhile to keep things shut away or allow the tourists to have the experience with the risk of having it destroyed' (Marquez 2006). There is a very fine line that tourists and tour operators must walk if they choose to visit sites of historical significance. A participant from a cruise operator suggests that guidelines are absolutely required in wilderness areas and archaeological sites. Archaeologists who work on the cruise ships, academics, cruise ship operators and cruise industry personnel struggle with the dilemma of wanting to share the incredible cultural treasures that are dispersed throughout the Arctic with a very real fear of overexposing these national relics to tourists. The creation and implementation of a guideline that would provide direction for the industry would be a solution to the current struggles that many participants face in regards to sensitive archaeological sites. However, it is clear that many archaeological sites elsewhere in the world are used currently for tourism. Learned experience from those sites should facilitate the development of guidelines and operational procedures that enable tourism use without damage.

In 2005, for the first time, Nunavut actually required every cruise company that came in to the area and landed at a remote site to have an archaeologist, or someone designated as an archaeologist, on board the ship who was responsible for education relating to the sites. There had to be an application for a permit in advance to visit a site. The requirement to have an archaeologist on board each cruise ship was introduced to ensure that a qualified person who understands the true significance of sensitive archaeological sites will try to protect them. 
An example of the potential problems related to tourist visits to archaeological and historical sites comes from Herschel Island, off the northern Yukon coast. Here there is a rich cultural and historical heritage around Simpson Point and Pauline Cove and at Avadlek point at the southern end of the island, where there have been archaeological excavations (Herschel Island 2006). There are many structures which range in age from precontact Thule cultures and historic buildings and structures developed by Inuvialiut, commercial whalers, traders, missionaries and the North West Mounted Police (see Appendix 3 Herschel Island 2018 for an inventory). There are also four graveyards (two Inuvialiut and one whalers and one North West Mounted Police), which, because of frost heaving processes, require management. There are also artefacts as well as Pleistocene mammalian fossils, which are often found along the beaches as the permafrost melts and erodes. All these sites and artefacts are vulnerable to potential tourist pressure, including trampling of the vegetation, destruction of structures and collection of artefacts. Currently the numbers of tourist visitors to Herschel Island is low (Herschel Island 2018) because of the difficulty of access, and number of cruise ships visiting over the last ten years has only been between one and three per year, with the number of visitors from these ships ranging from a low of 104 in 2005 to 534 in 2013. The total number of independent tourist ranged from a low of 22 in 2014 to 179 in 2006, and the number of tourist days ranged from a low of 42 in 2008 to 295 in 2006. Nevertheless, despite what we say in the next paragraph, management of cultural and historical sites visited by tourists, particularly cruise tourists, needs careful monitoring throughout the Canadian Arctic, and education does remain the key to preservation and conservation of these sites.

There seems to be hope in that Manley et al. (2017) found that, unlike mainstream cruises, tourists on expedition cruises to the Canadian Arctic are motivated by opportunities for novel experience and for learning. The educational programme offered by expedition cruise companies was an important component of their cruise experience. It was found that this programme has positively impacted cruise tourist attitudes, behaviours and knowledge post-cruise. These findings should encourage cruise companies to improve their educational offerings (i.e., preparedness, programme quality, level of engagement) to meet the expectations of their clientele, thereby transferring critical knowledge of environmental stewardship. It was suggested by Maher (2012) that this area of education of the clientele was being done well by operators in the Canadian Arctic. The use of the 'Linblad pattern' on these small vessels with zodiac trips to sites may help to creating a behavioural code, even if none exists in the regulations. There is a positive community engagement/educational opportunity for Inuit to dispel myths about living in, and their relationship to, the Arctic environment. In some communities a regular audience of cruise visitors to traditional throat singing, Arctic sports and drum dancing activities will help to make the tourists understand the local culture both in the past and present. This should again help in environmental stewardship by the participants.

\section{Conclusions}

In this chapter the Canadian arctic has been defined and described and the tourist numbers for the various regions estimated, including a summary of the strengths, weaknesses and threats to the tourist industry, as well as the opportunities for development. The impact of adventure tourism on wildlife has been described in detail. The impacts of polar bear hunting and its management controls were discussed whilst polar bear viewing, especially around Churchill is a major industry. The potential impacts and their management have been described here too. The spread of giardia and other declining factors for musk oxen on Banks Island have been described, and the possible role of tourism in the spread of giardia is noted.

Impacts of adventure tourism have been documented, including beluga whale viewing around Churchill and there have been con- 
flicts with traditional Inuit beluga hunting and tourists described from the Yukon. Ways of managing both viewing and the conflicts have been outlined. The human impacts on narwhal seem limited, but further research is needed here. Seal viewing and its management have been documented whilst there are potential impacts on shorebirds and cliffnesting birds from tourists, and the management guidelines for seabird viewing have been described. The usual impacts on tundra vegetation are apparent, particularly from offroad vehicles.

Examples of aboriginal cultural tourism have been described, including the development of world-class mountain bike trails near Carcross in the Yukon. The development of Canadian Arctic pleasure craft tourism and cruise tourism is described in the light of climate change and the opening up of more ocean to shipping. The management concerns regarding both sectors are discussed. Finally, how to maintain and manage the increased tourism at archaeological sites is discussed.

\section{References}

Belik, V. (2013). Our annual tourism report card, up here business 118. www.upherebusiness.ca

Bennett, J. (2017). What's killing muskox in the Arctic islands? www.canadiangeographic.ca/article/ whats-killing-musk-ox-arctic-islands

Blane, J. M., \& Jackson, R. (1994). The impact of ecotourism boats on the St. Lawrence beluga whales. Environmental Conservation, 2, 267-269.

Buckley, R. E. (2005). In search of the narwhal: Ethical dilemmas in ecotourism. Journal of Ecotourism, 4, 129-134.

Buckley, R. E. (2010). Ethical ecotourism: The narwhal dilemma revisited. Journal of Ecotourism, 9, 169-172.

Chanteloup, L. (2013). Wildlife as a tourism resource in Nunavut. Polar Record, 29, 240-248.

City of Thompson, Manitoba. (2012). Sustainable community development plan, Thompson, Manitoba. City of Thompson, MB.

Cucknell, A.-C., Boisseaau, O., \& Moscrop, A. (2015). A review of the impact of seismic survey noise on narwhal and other Arctic cetaceans. Report prepared for Greenpeace Nordic by Marine Conservation Research Ltd, 146pp.
Curtin, S., Richards, S., \& Westcott, S. (2009). Tourism and grey seals in South Devon: Management strategies, voluntary controls and tourists' perceptions of disturbance. Current Issues in Tourism, 12, 59-81.

Datapath. (2007). Nunavut exit survey. Marsh Lake, Yukon: Datapath Consulting.

DIAND (Department of Indian and Northern Affairs, Canada). (1984). Beaufort environmental monitoring Prospects 1983-4. Final Report, DIAND, Ottowa.

Dowsley, M. (2009a). Inuit-organised polar bear sport hunting in Nunavut territory, Canada. Journal of Ecotourism, 8, 161-175.

Dowsley, M. (2009b). Polar bear management in Nunavut and Nunavik, chapter 17, 215-232. In M. Freeman $\&$ L. Foote (Eds.), Inuit polar bears and sustainable use. Local, national and international perspectives. Edmonton: CCI Press, University of Alberta.

Dowsley, M., \& Wenzel, G. W. (2009). The time of most bears: A co-management conflict in Nunavut. Arctic, 61, 177-189.

Dressler, W. H. (1999). Nature-based tourism and sustainability in the Beaufort delta region, N.W.T.: An analysis of stakeholder perspectives tourism and sustainability. Master of Natural Resources Management, University of Manitoba, Winnipeg, MB, 297pp.

Dressler, W. H., Berkes, F., \& Mathias, J. (2001). Beluga hunters in a mixed economy: Managing the impacts of nature-based tourism in the Canadian Western Arctic. Polar Record, 37, 35-48.

Duerner, G. M., Laidre, K. L., \& York, G. S. (eds.). (2018). Polar bears. Proceedings of the 18th working meeting of the ICUN/SSC polar bear specialist group, 7-11 June 2016, Anchorage, AK. Occasional paper of the ICUN species survival commission No 63, 207pp, Gland, Switzerland and Cambridge.

Dyck, M. G. (2001). Effects of tundra vehicle activity on polar bears (Ursus maritimus) at Churchill, Manitoba. Master of Resource Management thesis, University of Manitoba, 149pp.

Dyck, M. G., \& Baydack, R. K. (2004). Vigilance behaviour of polar bears (Ursus maritimus) in the context of wildlife viewing activities at Churchill, Manitoba, Canada. Biological Conservation, 116, 343-350.

Eckhardt, G. (2005). The effects of ecotourism on polar bear behavior (46pp). MSc thesis, University of Central Florida, Orlando, FL. Electronic Theses and Dissertations 311. http://stars.library.ucf.edu/etd311

Edington, J., \& Edington, M. 1986. Ecology, recreation and tourism (200pp). Cambridge, MA: Cambridge University Press.

Environment Canada and CWA. (2001). Guidelines for seabird colony viewing by cruise ships. Iqualit, NU.

Fast, H., Mathia, J., \& Storace, F. (1998). Marine conservation and beluga movement in the Inuvialuit Settlement Region: Can marine protected areas play a role? Unpublished report prepared for the Fisheries Joint Management Committee, NWT, Inuvik.

Fikkan, A., Osherenko, G., \& Arikainen, A. (1993). Polar bears: The importance of simplicity. In O. Young \& G. Osherenko (Eds.), Polar politics: Creating inter- 
national environmental regimes (pp. 96-151). Ithaca: Cornell University Press.

Fishman, S. (1994). The effects of aircraft overflight on the enjoyment of visitors to National Parks (pp. 32-37). Department of Recreation and Leisure Studies. Visitor activity branch, National Parks Canada, Department of Canadian Heritage.

FJMC (Fisheries Joint Management Committee). (1994). Beaufort Sea Beluga Management Plan. Inuvik, NT.

FJMC (Fisheries Joint Management Committee, Canada). (1998). Beaufort Sea beluga management plan (3rd ed.). Inuvik, Canada: Fisheries Joint Management Committee.

FJMC (Fisheries Joint Management Committee). (2013). Beaufort Sea Beluga Management Plan. Amended 4th Printing, Inuvik, NT, 46pp.

Foote, L., \& Wenzel, G. (2008). Conservation hunting concepts, Canada's Inuit, and polar bear hunting. In B. Lovelock (Ed.), Tourism and the consumption of wildlife. Hunting, shooting and sport fishing (pp. 115128). London/New York: Routledge.

Foote, L., \& Wenzel, G. W. (2009). Polar bear conservation hunting in Canada: Economics, culture and unintended consequences. Chapter 1. In M. Freeman \& L. Foote (Eds.), Inuit polar bears and sustainable use. Local, national and international perspectives (pp. 13-24). Edmonton: CCI Press, University of Alberta.

Forbes, B. C. (1998). Cumulative impacts of vehicle traffic on high Arctic tundra: Soil temperature, plant biomass, species richness and mineral nutrition. PERMAFROST Seventh International Conference Proceedings, Collection Nordicana No. 55, 269-274.

Fraker, M., Sergaent, D., \& Hoek, W. (1997). Bowhead and white whales in the southern Beaufort Sea. Beaufort Sea project. Department of Fisheries and the Environment.

Freeman, M., \& Foote, L. (eds.). (2009). Inuit polar bears and sustainable use. Local, national and international perspectives, CCI Press, University of Alberta, 249pp.

Government of Newfoundland and Labrador. (2011). Profile of non-residents visiting the Labrador region. St Johns, Government of Newfoundland and Labrador.

Government of NWT. (2014). NW territories mineral development strategy, NWT Industry, Tourism and Investment, 31pp, Yellowknife. www.iti.gov.nt.ca/ sites/iti/files/nwt_mineral_development_strategy.pdf

Government of NWT. (2017). North West territories geological survey strategic plan 2017-022, Yellowknife.

Government of the North West Territories Industry, Tourism and Investment. (2009). Tourism within the economy. Economic Trends, Summer, Yellowknife.

Hall, C. M., \& Saarinen, J. (2010a). Polar tourism: Definitions and dimensions. Scandinavian Journal of Hospitality and Tourism, 10, 448-467.

Hall, C. M., \& Saarinen, J. (2010b). Polar tourism and change: Climate, environments and experiences. London: Routledge.

Hall, C. M., James, M., \& Wilson, S. (2010). Biodiversity, biosecurity, and cruising in the Arctic and sub-Arctic. Journal of Heritage Tourism, 5, 351-364.

Hampton, B., \& Cole, D. (1988). Soft paths, national outdoor leadership school, Stackpole Books.
Herrero, J., \& Herrero, S. (1997). Visitor safety in polar bear viewing activities in the Churchill region of Manitoba, Canada. BIOS environmental research and planning limited for Manitoba natural resources and parks Canada.

Herrero, S. (2002). Bear attacks: Their causes and avoidance. New York: Lyons Press.

Herrero, S., Smith, T., DeBryun, T. D., Gunther, K., \& Matt, C. A. (2005). From the field: Brown bear habituation to people-safety, risks, and benefits. Wildlife Society Bulletin, 33, 362-373.

Herschel Island Qikiqtanuk Territorial Park Management Plan. (2006). Yukon environment, 54pp. www.env. gov.yk.ca/.../documents/herschel-managementy-plan. pdf

Herschel Island-Qikiqtanuk Territorial Park Management Plan. (2018). Revised draft, Yukon environment, 43pp. www.gov.yk.ca/pdf/Herschel-Island-Qikiqtanukmanagement-Draft-Plan.pdf

Hinch, T., \& Butler, R. (1996). Indigenous tourism: A common ground for discussion. In R. Butler \& J. Hinch (Eds.), Tourism and indigenous peoples (pp. 3-21). London: International Thomsom Business Press.

Hopkins, J. B., Herrero, S., Schideler, R. T., Gunther, K. A., Schwartz, C. C., \& Kalinowski, S. T. (2010). A proposed lexicon of terms and concepts for humanbear management in North America. Ursus, 21, 154-168.

Humane Society of the USA. (2013). On thin ice: The dangerous impact of allowing polar bear trophy imports, 23pp. www.humanesociety.org/assets/pdfs/ legislation/polar_bear_imports_112012pdf

International Mountain Bike Association. (2012). IMBA epic rides. http://www.imba-com/epic/rides

Isaacs, J. C. (2000). The limited potential of ecotourism to contribute to wildlife conservation. The Wildlife Society Bulletin, 28, 61-69.

Johnston, M. E. (1995). Patterns and issues in Arctic and sub-Arctic tourism. In C. M. Hall \& M. E. Johnston (Eds.), Polar tourism in the Arctic and Antarctic regions (pp. 27-42). Chicheter: Wiley.

Johnston, M., Dawson, J., Stewart, E., \& De Souza, E. (2013). Strategies for managing Arctic pleasure craft Tourism: A scoping study. Report to Transport Canada. http://www.arctictourismandclimate.lakehead.ca

Klein, R. A. (2010). The cruise sector and its environmental impact. In C. Schott (Ed.), Tourism and the implications of climate change: Issues and actions (pp. 113-130). Bingley: Emerald Group Publishing.

Knight, R. L., \& Gutzwiller, K. J. (Eds.). (1995). Wildlife and recreationists: Coexistence through management and research. Washington D.C: Island Press.

Kovacs, K. M., \& Innes, S. (1990). The impact of tourism on harp seals (Phoca groenlandica) in the Gulf of St. Lawrence, Canada. Applied Animal Behaviour Science, 26, 15-26.

Kutz, S. J., Thompson, R. C. A., Polley, R., Kandola, K., Nagy, J., Wielinga, C. M., \& Elkin, B. T. (2008). Giardia assemblage A: Human genotype in musk oxen in the Canadian Arctic. Parasites and Vectors, 1, 32. https://doi.org/10.1186/17546-3505-1-32. 
Labrun, P., \& Debichi, C. (2018). Western Hudson Bay and its Beluga estuaries. Protecting abundance for $a$ sustainable future. Oceans North, 42pp.

Lair, S. (2013). Review of the status of the Beluga whales in the St. Lawrence River estuary. Blog of the Canadian Wildlife Health Cooperative. http://blog.healthywildlife.ca/review-of-the-status-of-beluga-whales-in-thest-lawrence-river-estuary/.

Lasserre, J., \& Têtu, P.-B. (2015). The cruise tourism industry in the Canadian Arctic: Analysis of activities and perceptions of cruise ship operators. Polar Record, 51, 24-38.

Lemelin, R. H. \& Wiersma, R. C. (2005). Interviews with the polar bear viewer. Published Abstract, 11th Canadian Congress on Leisure Research, Nanino, British Columbia, Canada, 17-20. http://www.lin.ca/ resource/html/cclr\%2011/CCLR11-80.pdf

Lemelin, R. H., Dawson, J., Stewart, E. J., Maher, P., \& Luck, M. (2010). Last-chance tourism: The boom, doom, and gloom of visiting vanishing destinations. Current Issues in Tourism, 13, 477-493.

Lentfer, J. (1974). Discreteness of Alaska polar bear populations. International Congress of Game Biologists, 11, 323-329.

Lunn, N. J., \& Stirling, I. (1985). The significance of supplemental food to polar bears during the ice free period of Hudson Bay. Canadian Journal of Zoology, 63, 2291-2297.

Maher, P. T. (2012). Expedition cruise visits to protected areas in the Canadian Arctic: Issues of sustainability and change for an emerging market. Tourism Review, $60,55-70$.

Manitoba Western Hudson Bay Ad Hoc Beluga Habitat Sustainability Plan Committee. (2016). Manitoba's Beluga habitat sustainability plan, Manitoba conservation and water stewardship. Winnipeg, MB, 30pp.

Manley, B., Elliot, S., \& Jacobs, S. (2017). Expedition cruising in Canadian Arctic: Visitor motives, and the influence of education programming on knowledge, attitudes and behaviours. Resources, 6, 23. https://doi. org/10.3390/resources6030023.

Marquez, J. (2006). An analysis of cruise ship management policies in parks and protected areas in the eastern Canadian Arctic (120pp). MA in recreation and leisure studies, University of Waterloo, Waterloo, Ontario, Canada.

Mathias, J., \& Fast, H. (1998). Options for a marine protected area in the Inuvialuit Settlement Region: Focus on beluga habitat. Report prepared for the Inuvialuit Game Council on behalf of the Fisheries Joint Management Committee, NWT, Inuvik.

Mieczkowski, Z. (1995). Environmental issues of tourism and recreation. Lanham: University Press of America, 566pp.

Nirlungayuk, G., \& Lee, D. S. (2009). A Nunavut Inuit perspective on Western Hudson Bay. Polar bear management and the consequences for conservation hunting. Chapter 10, 135-142. In M. Freeman \& L. Foote (Eds.), Inuit polar bears and sustainable use. Local, national and international perspectives. Edmonton: CCI Press, University of Alberta.

North West Territories Industry, Tourism and Investment. (2011). Tourism 2015 new directions for a spectacular future.

North West Territories Marketing Plan 2018-19, Yellowknife.

Northern Development Ministers Forum. (2008, August 27-28). Developing the tourism potential of Canada's North. Yellowknife (NWT).

Notzke, C. (1999). Indigenous tourism development in the Arctic. Annals of Tourism Research, 26, 55-76.

Nunavut Tourism. (2012). Tunngasaiji: A tourism strategy for Nunavumiut. Nunavut Tourism, 54pp

Nunavut Tourism. (2016). Nunavut Visitor Exit Survey 2015 Final Report, Insignia, Nunavut Tourism, 85pp.

O’Neil, B., Williams, P., Morten, K., Kunin, R., Gan, L., \& Payer, B. (2015). National aboriginal research project 2015. Economic impact of aboriginal Tourism Canada. Aboriginal Tourism Association of Canada (ATAC), 196pp.

Peacock, E., Derocher, A. E., Thiemann, G. W., \& Stirling, I. (2011). Conservation and management of Canada's polar bears (Ursus maritimus) in a changing Arctic. Canadian Journal of Zoology, 89, 371-385.

Pizzolato, L., Howell, S., Dawson, J., Copland, L., Derkson, C., \& Johnston, M. E. (2013). Climate change adaption assessment for transportation in Arctic waters (CATAW), scoping study. Summary report prepared for Transport Canada, Ottowa.

Richard, P. 2005. An estimate of the Western Hudson Bay beluga population size in 2004. DFO Canadian science advisory secretariat research document 2005/17.

Robbins, M. (2007). Development of tourism in Arctic Canada. In J. M. Snyder \& B. Stonehouse (Eds.), Prospects for polar tourism (pp. 84-101). Wallingford: CABI.

Rowsell, B., \& Maher, P. T. (2017). Uniqueness as a draw for riding under the midnight sun. Chapter 23, 221-229. In K. Latola \& H. Savela (Eds.), The interconnected ArcticUArctic congress 2016. Cham: Springer Polar Sciences.

Shadbolt, T., Cooper, E. W. T., \& Ewins, P. J. (2015). Breaking the Ice: International trade in narwhals, in the context of a changing Arctic. Toronto and Ontario: TRAFFIC and WWF Canada Report, 126pp.

Snyder, J. M. (2007). Economic roles of polar tourism. In J. Syder \& B. Stonehouse (Eds.), Prospects for polar tourism. Wallingford: CABI.

Stewart, E. J., \& Dawson, J. (2010). A matter of good fortune? The grounding of the clipper adventurer in the Northwest Passage. Arctic, 64, 263-267.

Stewart, E. J., Tivy, A., Howsell, S. G. L., Dawson, J., \& Draper, D. (2010). Cruise tourism and sea ice in Canada's Hudson Bay region. Arctic, 63, 57-66.

Stewart, E., Dawson, J., Howell, S., Johnston, M., Pearce, T., \& Lemelin, R. (2012). Sea ice changes and cruise tourism in Arctic Canada's North West Passage: Implications for local communities. Polar Geography. https://doi.org/10.1080/1088937X.2012.705352. 
Stirling, I., Jonkel, C. J., Smith, P., Robertson, R., \& Cross, D. 1977. The ecology of the polar bear (Ursus maritimus) along the western coast of Hudson Bay. Canadian Wildlife Service Occasional Paper 33, 634pp.

Talarico, D., \& Mossop, D. (1988). Herschel island avifauna monitoring project. Ottowa, Canada: Fish and Wildlife Service, $17 \mathrm{pp}$.

Talarico, D., \& Mossop, D. (1998). Herschel Island avifauna monitoring project. Fish and Wildlife Service, $17 \mathrm{pp}$.

The Churchill Beluga Whale Tour Operators Association and the Town of Churchill. (2015). Impacts of proposed federal marine regulations on the world renowned Churchill Manitoba Beluga Tourism experience. Manitoba, 30pp.

Thorburn, A. (1920). British mammals. London: Longman, Green and Company, 2 vols.

Tourism Quebec. (2010). Regional statistics-Nunavik. Quebec, Quebec City, Government of Quebec. http:// www.gouv.qc/ca/portail/quebec/pgs/commun/portrait/ tourisms/?lang=en

Tourism Yukon. (2016). Tourism Yukon end of year report. http://www.tc.gfov.yk.ca/2016.Tourism-YukonYear-End-Report

Transportation Safety Board of Canada. (1996). Marine reports 1996. www.tsb.gc.ca//eng/rapports-reports/ marine/1996m96h0016/m96h0016.asp
Tyrrell, M. (2006). More bears, less bears: Inuit and scientific perceptions of polar bear populations on the west coast of Hudson Bay. Études/Inuit/Studies, 30, 191-208.

Tyrrell, M. (2009). Guiding opportunity, identity: The multiple roles of the Aviat polar bear conservation hunt. In M. Freeman \& A. L. Foote (Eds.), Inuit, polar bears and sustainable use: Local, national and international perspectives (pp. 25-37). Edmonton: Canadian Circumpolar Institute Press.

Vongraven, D. (2009). Guest editorial; the ballyhoo over polar bears. Polar Research, 28, 223-226.

Watts, P. D., \& Ratson, P. S. (1989). Tour operator avoidance of deterrent use and harassment of polar bears. In Bear-people conflicts, proceedings of a symposium on management strategies (pp. 189-193). Yellowknife: North West Territories Department of Renewable Resources.

Webb, A. J. (1985). Environmental impact of all-terrain vehicles in the Cape Churchill wildlife management area. Master' thesis, University of Manitoba, Winnipeg, 182pp.

Wenzel, G. W., \& Bourgouin, F. (2003). Polar bear management in the Qikqtaaluk and Kitikmeot regions of Nunavut, Inuit outfitted hunting and conservation. Unpublished Report to the Department of Sustainable Development, Government of Nunavut. 